Prepared for the U.S. Department of Energy

under Contract DE-AC05-76RL01830

\title{
Radiation Source Replacement Workshop
}

\author{
JW Griffin \\ TL Moran \\ LJ Bond
}

December 2010

Pacific Northwest

NATIONAL LABORATORY

Proudly Operated by Battelle Since 1965 


\title{
DISCLAIMER
}

This report was prepared as an account of work sponsored by an agency of the United States Government. Neither the United States Government nor any agency thereof, nor Battelle Memorial Institute, nor any of their employees, makes any warranty, express or implied, or assumes any legal liability or responsibility for the accuracy, completeness, or usefulness of any information, apparatus, product, or process disclosed, or represents that its use would not infringe privately owned rights. Reference herein to any specific commercial product, process, or service by trade name, trademark, manufacturer, or otherwise does not necessarily constitute or imply its endorsement, recommendation, or favoring by the United States Government or any agency thereof, or Battelle Memorial Institute. The views and opinions of authors expressed herein do not necessarily state or reflect those of the United States Government or any agency thereof.

\author{
PACIFIC NORTHWEST NATIONAL LABORATORY \\ operated by \\ BATTELLE \\ for the \\ UNITED STATES DEPARTMENT OF ENERGY \\ under Contract DE-AC05-76RL01830 \\ Printed in the United States of America \\ Available to DOE and DOE contractors from the \\ Office of Scientific and Technical Information, \\ P.O. Box 62, Oak Ridge, TN 37831-0062; \\ ph: (865) 576-8401 \\ fax: (865) 576-5728 \\ email: reports@adonis.osti.gov

\footnotetext{
Available to the public from the National Technical Information Service, U.S. Department of Commerce, 5285 Port Royal Rd., Springfield, VA 22161 ph: (800) 553-6847 fax: (703) 605-6900

email: orders@ntis.fedworld.gov online ordering: http://www.ntis.gov/ordering.htm
}

This document was printed on recycled paper. 


\section{Radiation Source Replacement Workshop}

JW Griffin

TL Moran

LJ Bond

December 2010

Prepared for

the U.S. Department of Energy

under Contract DE-AC05-76RL01830

Pacific Northwest National Laboratory

Richland, Washington 99352 



\section{Abstract}

This report summarizes a Radiation Source Replacement Workshop in Houston, Texas, on October 27-28, 2010, which provided a forum for industry and researchers to exchange information and to discuss the issues relating to replacement of americium-beryllium $(\mathrm{AmBe})$, and potentially other isotope sources used in well logging.

The workshop had about 60 attendees, with the majority from the petrochemical well logging sector. Federal government speakers introduced terrorism scenarios, including recent threats and how stolen radioactive sources might be used. A presentation by the U.S. Environmental Protection Agency (EPA) stimulated considerable discussion around possible nuclear source alternatives being pursued. U.S. Nuclear Regulatory Commission (NRC) regulation questions specific to the well logging industry in Texas were presented.

A series of presentations reported development/improvement of electronic neutron sources and described products in the pipeline industry (both gamma and neutron sources) with potential application to the well logging industry.

The Nuclear Special Interest Group (SIG) of the Society of Petrophysicists and Well Log Analysts (SPWLA) was introduced as an excellent vehicle for staying abreast of nuclear needs and developments in the petrochemical well logging industry.

Presentations then followed on the seismoelectric well logging method, the use of local gravity measurements for measuring rock density and then an overview of electronic radiation sources (both $\mathrm{x}$-ray/gamma photon and neutron) and a discussion of a combined nuclear magnetic resonance (NMR)/acoustics tool for source-less porosity measurements. It was reported that NMR tools will not make nuclear logging obsolete.

Electronic deuterium-tritium (D-T) neutron sources and legacy porosity logs acquired with AmBe sources were discussed and it was shown that they can be compared with logs acquired using high energy D-T neutron sources. However, some in the industry dispute this point and are looking for data in logs that look like historic records. Finally, the presentation by Ron Cherry from Halliburton pointed out that nuclear density measurements are necessary to correctly interpret NMR log data.

Group discussions both during and after the presentations made clear the following points:

- New AmBe neutron sources are expensive and hard to obtain.

- ${ }^{252} \mathrm{Cf}$ looks to be a near term neutron source replacement because the neutron energy is comparable to AmBe and because the cost is only $20 \%$ of that for an $\mathrm{AmBe}$ source $\left({ }^{252} \mathrm{Cf}\right.$ sources now cost what $\mathrm{AmBe}$ sources used to cost). Some uncertainty exists regarding the future availability of ${ }^{252} \mathrm{Cf}$.

- NMR tools do not eliminate the need for nuclear logging. ${ }^{137}$ Cs gamma backscatter measurements are still required for rock density. NMR logging is expensive due to the requirement for slow logging speeds. 
- The smaller well logging companies do not have access to NMR tools or electronic neutron sources. They rely heavily on $\mathrm{AmBe}$ sources but can potentially accommodate ${ }^{252} \mathrm{Cf}$ sources assuming they are available at reasonable cost. 


\section{Acknowledgments}

The authors acknowledge and thank the SEG and University of Houston Well Logging Laboratory for sponsoring this workshop. 



\section{Acronyms and Abbreviations}

$\mathrm{AmBe}$

CNT

D-T

EPA

GTRI

HI

IDD

ITAR

LANL

LINAC

MCNP

NA-22

NMR

NRC

PIR

PNNL

RMS

SBIR

SIG

SPWLA americium-beryllium

carbon nanotube

deuterium-tritium

U.S. Environmental Protection Agency

Global Threat Reduction Initiative

hydrogen-index

in-device delay

International Traffic in Arms Regulations

Los Alamos National Laboratory

linear accelerator

Monte-Carlo N-Particle

U.S. Department Energy, National Nuclear Security Administration, Office of Nonproliferation and Verification R\&D

nuclear magnetic resonance

U.S. Nuclear Regulatory Commission

passive infrared sensor

Pacific Northwest National Laboratory

remote monitoring system

Small Business Innovation Research

Special Interest Group

Society of Petrophysicists and Well Log Analysts 



\section{Contents}

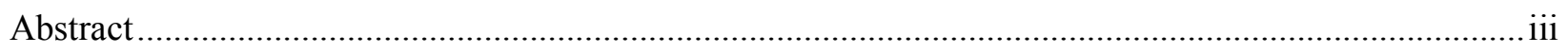

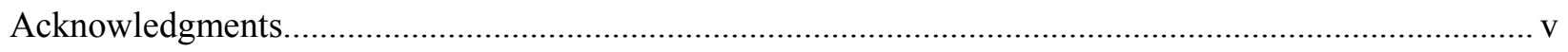

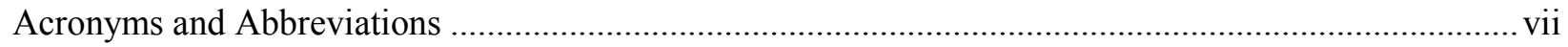

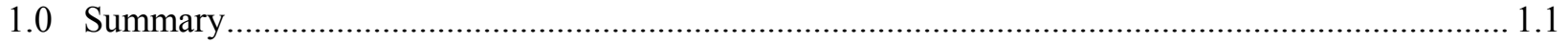

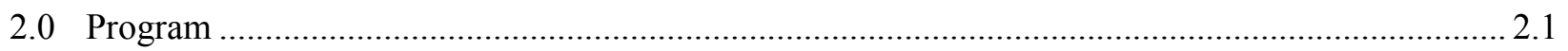

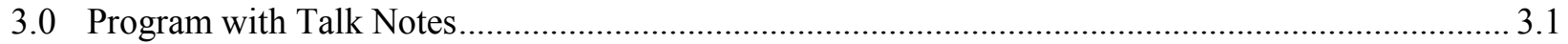

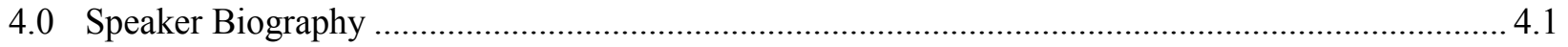

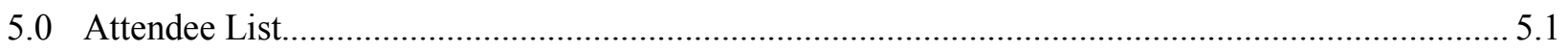

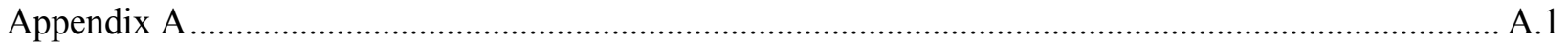





\subsection{Summary}

Please find below a brief summary report on the Radiation Source Replacement Workshop held at the University of Houston in October 2010:

1) The workshop was well-attended. We numbered over 70 registrants and had probably 60 attendees, largely from the petrochemical well logging sector. Clearly there is a lot of interest in what the U.S. Department Energy, National Nuclear Security Administration, Office of Nonproliferation and Verification R\&D (NA-22) (and the other government speakers) had to say.

2) The terrorism scenario presentations by Bill Rhodes and Joe Schwartzel were right on target. The industry participants were especially interested in learning more about recent threats and how stolen radioactive sources might be used. There was consensus that the "insider threat" was potentially the most severe.

3) Presentations by Madeleine Nawar (U.S. Environmental Protection Agency, EPA) and Rachel Browder (U.S. Nuclear Regulatory Commission, NRC Arlington, Texas, field office) stimulated considerable discussion. The audience was very interested in hearing about the nuclear source alternatives being pursued at the EPA. Since many of the industry participants were from the Houston area, Rachel Browder was able to answer NRC regulation questions specific to the well logging industry in Texas.

4) Both Greg Dale and Thomas Schenkel did a good job of conveying their efforts to development/improve electronic neutron sources. During the second day of the workshop (industry presentations) Greg and Thomas participated in numerous dialogues, which served to clarify industry requirements for electronic gamma and neutron sources. Consequently, they both received considerable guidance on how they can make their R\&D efforts more relevant to the well logging industry. Because the Los Alamos National Laboratory (LANL) work involves building a down-hole tool, several of the industry participants viewed Greg's work as too applied ("Leave the tool building to us....you lab guys should be doing the science").

5) The presentations by former and current Small Business Innovation Research (SBIR) awardees, Pedro Frigola (Radiabeam) and Ka-Ngo Leung (Berkion Technology) stimulated a lot of discussion. Pedro has several products in the pipeline (both gamma and neutron sources) with potential application to the well logging industry. Dr. Leung's source development work was less mature.

6) Dr. Ahmed Badruzzaman, Chevron, made it clear that the Nuclear Special Interest Group (SIG) of the Society of Petrophysicists and Well Log Analysts (SPWLA) is an excellent vehicle for staying abreast of nuclear needs and developments in the petrochemical well logging industry. The Nuclear SIG meets twice per year and, in our opinion, the NA-22 source replacement effort would greatly benefit from having a representative at those meetings. Ahmed also pointed out that oil companies want to move away from the use of chemical radiation sources - the financial liability is simply too high. He related the case of a recently abandoned well in Africa where a Cs gamma source "got stuck" downhole. Chevron decided against attempting retrieval because the risk of a source breach was too high. The well was sealed. Total cost $\$ 25 \mathrm{M}$. He compared this to the case of a stuck Cs source in a California well where the source was breached, resulting in mud and drill pipe contamination. That event has resulted in a 
300-year (ten ${ }^{137} \mathrm{Cs}$ half-lives) environmental monitoring requirement to verify no transport of contamination (cost $\$ 100$ 's of millions of dollars).

7) The presentation by Dr. Richard Clarke on the seismoelectric well logging method generated very little interest (there were no questions after his talk). This non-nuclear porosity method is either poorly understood or deemed to be inapplicable by the well logging professionals in attendance. Recall that the Pacific Northwest National Laboratory (PNNL) external project review committee urged Dr. Bond's team to explore this method. Based on the workshop participant response, we recommend that no further effort be expended on the seismoelectric method.

8) Dr Terry Hagiwara, Aramco Services, discussed the use of local gravity measurements for measuring rock density. He did an excellent job of pointing out the measurement challenges associated with such a weak signal. Unfortunately, available sensor technology simply will not permit gravity measurements to be made with such high sensitivity in the hostile environment of the borehole. We recommend no further pursuit of downhole gravity measurements.

9) The speakers from Baker Hughes, Allen Gilchrist and Songhua Chen, provided respectively: 1) an overview of electronic radiation sources (both x-ray/gamma photon and neutron); and 2) a discussion of a combined NMR/acoustics tool for source-less porosity measurements. Dr. Gilchrist pointed out that electronic radiation sources are very energy-inefficient and cannot replace the ${ }^{137} \mathrm{Cs}$ gamma-gamma measurements of rock density (and subsequently rock porosity). True source-less density measurements require significant technology advances prior to becoming a reality. Dr. Chen discussed NMR measurements and made three points: a) porosity derived from NMR logs may be adequate for liquidbearing formations as long as quantification of the fluid types is adequate; $b$ ) the error in NMR-derived porosity for low hydrogen-index (HI) fluid bearing formations is proportional to $1 / \mathrm{HI}$ and; c) NMRcalibrated acoustic porosity is a better approach than NMR alone for low HI formation fluids. In summary, NMR tools will not make nuclear logging obsolete.

10) The two Schlumberger speakers, David Madio and Chris Stoller, discussed electronic D-T neutron sources and showed that legacy porosity logs acquired with AmBe sources can be compared with logs acquired using high energy D-T neutron sources. This fact negates the common complaint that “AmBe logs don't look like D-T logs" because, using the Schlumberger process, the logs can be made to look alike. However, some in the industry dispute this point and are looking for data in logs that look like historic records.

11) Finally, the presentation by Ron Cherry from Halliburton pointed out that nuclear density measurements are necessary to correctly interpret NMR log data. Hence, nuclear measurements are used as a reference for NMR and other formation measurements. He also pointed out that NMR logging is slow (and therefore expensive).

Group discussions both during and after the presentations made clear the following points:

- New AmBe neutron sources are hard to obtain. Price is $\sim \$ 100 \mathrm{~K} .{ }^{252} \mathrm{Cf}$ looks to be a near-term neutron source replacement because the neutron energy is comparable to AmBe and because the cost is only $20 \%$ of that for an $\mathrm{AmBe}$ source $\left({ }^{252} \mathrm{Cf}\right.$ sources now cost what AmBe sources used to cost). Some uncertainty exists regarding the future availability of ${ }^{252} \mathrm{Cf}$. 
- NMR tools do not eliminate the need for nuclear logging. ${ }^{137}$ Cs gamma backscatter measurements are still required for rock density. NMR logging is expensive due to the requirement for slow logging speeds.

- The smaller well logging companies do not have access to NMR tools or electronic neutron sources. They rely heavily on AmBe sources but can potentially accommodate ${ }^{252} \mathrm{Cf}$ sources assuming they are available at reasonable cost $(\$ 20 \mathrm{~K})$. 



\subsection{Program}

Wednesday, October 27

"The National Security Perspective and Federally Funded R\&D"

8:00 Continental Breakfast

8:30-8:45 Welcome and Introductions

Dr. Richard Liu, U of H Well Logging Laboratory, University of Houston

8:45-9:00 Dr. Jeff Griffin/Dr. Leonard Bond, Pacific Northwest National Laboratory

"Goals of the NNSA Radiation Source Replacement Project"

9:00-9:30 Dr. Bill Rhodes, Sandia National Laboratory

"The RDD Threat and the Global Threat Reduction Initiative's (GTRI) Domestic

Security Efforts"

9:30-10:00 Dr. Joe Schwartzel, Consultant

"The GTRI Well-Logging Security Initiative - A Government-Industry Collaboration"

10:00-10:20 Ms. Madeliene Nawar, U.S. Environmental Protection Agency

"Alternative Technology Initiative"

10:30-11:00 Coffee Break

11:00-11:30 Ms. Rachel Browder, U.S. Nuclear Regulatory Commission

"NRC Perspective on Well-logging Source Use and Security"

11:30-12:00 Dr. Thomas Schenkel, Lawrence Berkeley Laboratory

"Development of an Ultra Compact Neutron Source"

Noon-1:30 Lunch

1:30-1:45 Ms. Frances Keel, U.S. DOE NNSA Nonproliferation and Verification R\&D (NA-22)

"Welcome and Goals of Workshop"

1:45-2:15 Dr. Gregory Dale, Los Alamos National Laboratory

"Piezoelectric Transformer Neutron Generator (PTNG) for Well Logging"

2:15-2:45 Dr. Pedro Frigola, Radiabeam Technologies

"Compact, Inexpensive, and Robust Low-Energy LINACs" (Phase II SBIR Grant FY2010)

2:45-3:15 Dr. Ka-Ngo Leung, Berkion Technology

"Compact Neutron/Gamma Generators for Well-logging" (Phase I SBIR Grant FY2009)

3:30-4:00 Panel Discussion - All Speakers 
Thursday, October 28

"Emerging Alternatives to Nuclear Well Logging"

8:00 Continental Breakfast

8:30-9:15 Dr. Ahmed Badruzzaman, Chevron

"Radioactive Sources in the Petroleum Industry: Applications, Concerns and Alternatives"

9:15-9:45 Dr. Richard Clarke, Groundflow Ltd

"Seismoelectric Well Logging"

9:45-10:15 Dr. Terry Hagiwara, Aramco Services

"Borehole Gravity for Density Measurements"

10:15-10:30 Coffee Break

10:30-11:15 Dr. Allen Gilchrist, Baker-Hughes

"Electronic Neutron Sources"

11:15-12:00 Dr. David Madio, Schlumberger

"Thermal Neutron Porosity Using Pulsed Neutron Measurements"

Noon-1:30 Lunch

1:30-2:00 Dr. Chris Stoller, Schlumberger

"Thermal Neutron Porosity Measurements Using a Pulsed D-T Generator in LWD and Wireline"

2:00-2:30 Dr. Songhua Chen, Baker-Hughes

"NMR and Acoustics - An Integrated Solution for Sourceless Porosity"

2:30-3:00 Mr. Ron Cherry, Halliburton

"MRIL and Combinations with Other Logs to Obtain Accurate Porosity"

3:00-4:00 Panel Discussion - All Speakers 


\title{
3.0 Program with Talk Notes
}

\author{
Wednesday, October 27, 2010 \\ "The National Security Perspective and Federally Funded R\&D"
}

8:00 Continental Breakfast

8:45-9:00 "Goals of the NNSA Radiation Source Replacement Project"

Speaker: Dr. Jeff Griffin, Pacific Northwest National Laboratory

Issues/questions identified during Dr. Bond's presentation at the SEG meeting the previous week:

- Cost and availability of AmBe in US are issues. Can Russian sources be used in the US?

- Restrictions on AmBe transport are viewed as excessive (compared with Europe)

- D-T neutron generators are a "dual use" technology. Will there be restrictions on their deployment and use?

- Users want a neutron source with a spectrum that "looks like AmBe"

- Small logging companies are the most vocal about retaining AmBe for re-logging production wells

- Need validation of alternate or replacement neutron logging technologies

- Large companies dominate LWD and use of electronic neutron sources

9:00-9:30 “The RDD Threat and the Global Threat Reduction Initiative's (GTRI) Domestic Security Efforts" Speaker: Dr. Bill Rhodes, Sandia National Laboratory

Global Threat Reduction Initiative (GTRI) - Convert Reactors that have highly enriched fuels to use lower enrichment fuels

- IND vs. RDD

- IND - device that may be stolen that can produce nuclear yield - thousands of tons TNT equivalent, effects are wide (nuclear reaction), probability lower but consequences higher

- RDD - tens to hundreds of tons of TNT (chemical reaction), probability higher but consequences lower

- Insider threat - trend of insiders looking at terrorism to get a message across

- Summary of insider radiological incidents over the past 10 years....Radiological incidents stolen Cs137 in N. Caroling, Coworker attack with I192 in China, Aaria Siddiqui arrested w/ RDD Plans (Pakistan 2008), Dhiren Baarot - dirty bomb plot in UK, Cs137 source stolen in Extortion

- People are interested in these materials for making dirty bombs and other plans

- Materials of concern $-{ }^{137} \mathrm{Cs}$ (blood irradiation, sterilization), Cs salt is water soluble,${ }^{60} \mathrm{Co}$ (teletherapy and gamma knife - cancer treatments) metal not soluble, ${ }^{192} \mathrm{Ir}$ hard metal, ${ }^{241} \mathrm{Am}$ between soluble and metallic 
- Why would somebody steal these? - papers listed where these sources were available and used common safety/security protocols to keep out the hands of the general public

- Civilian soft targets/open environments, NNSA/DNDO has sponsored mock exercises with surrogate sources - takes minutes to steal these sources

- $\mathrm{RDD}$ consequences - $3000 \mathrm{Ci}$ of ${ }^{137} \mathrm{Cs}-2 \mathrm{rem}$ dose, contaminated area $1.2 \mathrm{~km}^{2}$ (blood irradiator in a hospital)

- With an explosive optimized device results are -2 rem dose, area $6.3 \mathrm{~km}^{2}$ but higher dose closer (up to $25 \mathrm{rem}$ )

- GTRI's Domestic Program - provide voluntary expertise in removal of disused or unwanted radioactive sources, voluntary security upgrades, training of local law enforcement, table top exercises where entire emergency response team works out a plan on how to handle the situation

- Process steps include volunteer (licensee), assess (NNSA), design, agree, contract, install, test/train, operate/maintain

- Sample security enhancements - remote monitoring system (RMS)-alarms trigger surveillance, passive infrared sensors (PIR), data seals - broken seal result in transmission of images and alarms are sent wirelessly, radiation detectors

- In-Device Delay (IDD)- passive barrier directly on the shielding, provides significant additional access delay compared to unhardened unit

- GTRI Alarm Response Training - done at Oakridge (Y12), pays all costs except for salary of participants, three day course that covers entire scenario (from the time source is stolen until it is returned - who to contact, who is in charge, DHS highly involved)

- Table top exercises - gather people together in a no-fault environment, see how different agencies react, FBI, DHS, DOE, NRC, local authorities (police), fire department,

- Oakridge - collects thousands of disused and unwanted sources - Cs, Co, Sr90, Am241, Pu238

\section{9:30-10:00 “The GTRI Well-Logging Security Initiative - A Government-Industry Collaboration" Speaker: Dr. Joe Schwartzel, Consultant (retired US Navy captain)}

- Key Points: Well Logging Security Initiative - partnered with DOE, Baker Hughes, Halliburton, Pathfinder, Schlumberger, Tucker Energy Services and, Weatherford International

- Why does NNSA care? - focus on ${ }^{241} \mathrm{Am}$ - source risk (portability, mobility, accessibility, half lives, prevalence (over 10,000 radioactive sources used in oil industry, dangerous alpha properties, curie level, history of theft)

- Sources used all over the world

- Security challenges in various areas: logging base camps - companies all over worlds, in transit from base camp secure area to drill site (by boat, helicopter, trucks), drill sites - other companies involved at drill site and drill site operator is in charge

- NRC came out with increased controls on Cat. 2 less than $16 \mathrm{Ci}$ sources

- April 2006 - conducted initial pilot security assessment with Weatherford in Abu Dhabi 
- Met with office of radiation and went to base, asked about typical security measures - need two persons to handle/transport radioactive sources for insure worker safety

- 2008 jointly drafted and GTRI promulgated the "Security and Control of High Activity Well Logging Sources Guidelines"

- June 2009 - A training video based on the guidelines document was promulgated to all partner companies (Weatherford assisted)

- Weatherford field operations - well managed operations, standardized procedures, security can build on safety programs for sources, risk management activities, relationships with local authorities, security provided by well site operator, coordinated route planning

- Security must reduce vulnerability to theft by detecting intrusion, assessing intrusion, delaying adversaries until appropriate forces can respond and by improving response capabilities

- GTRI (Global Threat Reduction Initiative) uses a "Target out” approach—concentrate security elements closest to the target materials.

- Recommendations included in guidelines : 1) hardened enclosures; 2) intrusion detection system; 3) closed circuit television; 4) prevention of insider theft (2-person rule); 5) high security locks;

6) locked out power; 7) duress (panic) buttons; 8) offsite alarm monitoring; 9) procedures;

10) response plans; 11) security training (consistent with other security procedures)

- MC\&A - Material Control and Accountability - two person rule included in procedures for access to sources, key control procedures, frequent source inventory

\section{Questions:}

Q: What is worst case scenario?

A: Worst case would be insider threat because company personnel have access to sources

10:00-10:30 “Alternative Technology Initiative" Speaker: Ms. Madeliene Nawar, US Environmental Protection Agency

\section{Key Points:}

- Overview - challenge - uncontrolled radioactive sources entering the public domain -

- Voluntary program

- Goal - minimize the number of isotopic sources in use by government, industry, and academia

- Focus on industrial sectors -

- Innovation - technical projects - foster development and introduction of alternative (nonchemical) radioactive sources into the market place...verification of new sources, market demonstration

- Focus on technical applications (e.g., industrial radiography) where potential for significant impact exists, both in number of application and in maturity of alternative programs

- Technical projects

- Portable gauges - cooperative effort between Gas Technology Institute and utility industrydemonstrated moisture density gauge 
- Fixed gauges

- Industry Radiography Camera

- Southwest Research Institute examined two alternative x-ray and ultrasonic imaging systems

- Manufacturer of device incorporated recommended changes to enhance compatibility

- Battelle Columbus involved in R\&D

- Third component- Partnerships - Collaboration with industry and government stakeholders

- What is needed?

- Rigorous assessment of cost-benefit of radioactive device compared with alternative devices, appropriate standards, knowledge among end users of alternatives, increased collaboration between government and industry, and need to address implementation barriers and consequences

- Integrating product stewardship and stakeholder practices/engagement, determine how to evaluate successes and failures, identify barriers to new technology acceptance

\section{Conclusions:}

- The Advanced Technology Initiative goal: 1) reduce risk by reducing number of sources used in industry and; 2) promote development and acceptance of radiation free devices

10:30-11:00 - Coffee Break

11:00-11:30 "NRC Perspective on Well-logging Source Use and Security" Speaker: Ms. Rachel Browder, US Nuclear Regulatory Commission

\section{Key Points:}

- NRC's Agreement State Program

- 37 Agreement states in the United States, NRC, and governors of each state, Section 274 of Atomic Energy Act

- What NRC regulates - medical uses, industrial uses, academic and research uses of radioactive materials

- Source Categorization - Category 1, Category 2 (tens to thousands of curies) $-{ }^{60} \mathrm{Co},{ }^{137} \mathrm{Cs},{ }^{192} \mathrm{Ir}$, ${ }^{241} \mathrm{Am}$

- Implement a risk-informed approach for security and control of radioactive materials

- Perform security assessments for irradiators, source manufacturing and distribution, medical facilities, universities, radiographers, and well loggers

- Specific actions to enhance source control include background checks, including finger printing, enhanced physical barriers and intrusion detection systems, coordination with local law enforcement, prompt notification of incidents 
- Well logging industry performance (2002-2010)-

- 2 occasions where sources were lost and not recovered (results of hurricane Katrina and Deepwater Horizon accident),

- 92 abandonments (multiple well-logging sources with each request),

- 1 lost and recovered well logging source during transportation,

- 1 incident where a source was lost in 35 feet of water and recovered,

- 2 incidents as a result of human error that contributed to occupational exposures while working on the drilling rig,

- 0 event reports of stolen well-logging sources during this period

- NRC concerns for the safety of well logging activities

- disposal of americium sources when no longer needed,

- vulnerability of transporting well logging sources to offshore platforms and lay barges (jurisdiction during transport is US Coast Guard, when the sources are on dock NRC assumes jurisdiction)

- concerns of sources staying on dock for many days (10) before pickup

- Proposed Rule on the Physical Protection of Byproduct Material - CFR Part 37 - new rule builds upon existing security requirements, takes into consideration lessons learned on the effectiveness of the implementation of the requirements, expands existing requirements for personnel background checks, physical protection during use, and physical protection while in transit

- NSTS - National Source Tracking System - - $107{ }^{241}$ Am being tracked but there are many other but there are many sources below Category 2 not being tracked. Source tracking expansion to Category 3 sources is being considered tracked but no decision has been made as of 2009

\section{Conclusions:}

- NRC is supportive of the US Government-funded short term and long term research and development of alternative technologies

\section{Questions:}

Q: How does NRC regulate companies overseas?

A: NRC does not regulate overseas activities. Baker Hughes staff member says logging companies operate to the most stringent country guidelines.

\section{1:30-12:00 "Development of an Ultra Compact Neutron Source" Speaker: Dr. Thomas Schenkel, Lawrence Berkeley Laboratory}

\section{Key Points:}

- Overview - LBL is being funded by DOE NNSA to develop neutron generators for radiological source replacement

- Fusion (electronic) sources include D-D (2.4 MeV), D-T (14 MeV), T-T (0-9MeV) 
- Components of neutron generators include: 1) ion source; 2) acceleration tube to achieve deuterium ion energies of $30-200 \mathrm{kev}$ and; 3 ) a target that can be deuterium loaded

- Penning ion sources exhibit low current density discharge, much room for improvement

- $\quad \mathrm{RF}$ driven proton source - very high atomic ion fraction but requires $\sim 100 \mathrm{~W}$ electrical power. Can operate sealed

- Permanent magnet microwave ion source

- Very high atomic ion fractions but also need $100 \mathrm{~W}$ electrical power, highest power efficiency

- Molecular dissociation and atomic ion formation - atomic vs. molecular ions, dissociation of hydrogen molecules only requires $4.52 \mathrm{eV}$ per molecule. Then ionize the atomic hydrogen for a $10 \mathrm{x}$ increase in neutron yield at the same beam current. Lower (electrical) power atomic ion formation using field enhancement effects at sharp tips (carbon nanotubes).

- Approach - Utilize field ion formation technology with sharp conductive tips. From one to one million tips-studied since the 50's, widely used in liquid metal ion sources and helium ion microscopes - integrate millions of self assembled tips for $>1 \mathrm{~mA}$ of deuterium ions per $\mathrm{cm}^{2}$

- Formation of $\mathrm{D}+$ ions is a two step process: 1) ionization and; 2) breakup ${ }^{2} \mathrm{D}$ to form $\mathrm{D}+$ ions

- Vision - Find surface conditions, materials, and tip geometries for efficient D formation by electric field enhanced catalytic dissociation and electron capture. Very attractive for forming deuterium ions since there is no molecular negative ion background in the beam. Attractive also because the local field enhancement requirements are expected to be much relaxed compared to those for positive ion formation.

- Approach - Test etched metal tips for baselining carbon nanotubes. Use hydrogen atom source to differentiate dissociation and ionization steps. Find surfaces for catalytic dissociation of deuterium molecules. Use surface pattern with tips for field enhancement

- Can create D+ and D- ions

- Utilize vertical array of carbon nanotubes (CNTs) - Suitable for rapid pattering on large areas. There are uniformity issues due to variations in tip height and sharpness. Observed reproducible field enhancement factors in electron emission for field emissions for a series of samples.

- Utilize etched silicon nanotip arrays - Exhibit high degree of uniformity over large array sizes, but field enhancement factor is smaller than for CNTs

- Approach - field ionization of D-T using millions of self assembled nanowires - Status - WARP-3D -Simulations of electrical field enhancement at single and multiple tips

- Neutron production from patterned CNT ensembles - few microamps of D+ current with deuterium source

- Neutrons detected with a calibrated ${ }^{3} \mathrm{He}$ detector

- Observe electrical spark damage to CNT ensembles

- Metal coatings protect CNTs from etching by atomic deuterium 


\section{Conclusions:}

- Outlook - systematic studies of D+ and D- formation and neutron production:

1) for a series of nanotip materials and geometries (CNTs, Si tips);

2) as a function of surface condition (coatings, work function control);

3) perform expanded simulations and;

4) investigate D+ and D- ion formation from D (atom) versus D2 (molecule)

- Goal

1) quantify neutron yields for series of optimized emitter types;

2) find tips that yield stable $D$ ion current of0 .1 to $1 \mathrm{~mA} / \mathrm{cm}^{2}$;

3) use this information to design/specify an ultra compact filed emission type neutron generator for radiological source replacement

\section{Questions:}

Q: What does this give us that we don't already have?

A: A more compact neutron source, not necessarily more neutrons

Q: Are you focused on T-T, D-T, or D-D

A: Focus is much broader... goal is to first test using deuterium (tritium)?

Q: Question for EPA - Are you just replacing one radioactive material $\left({ }^{241} \mathrm{Am}\right)$ with another

Q: What is the lifetime for these sources?

A: There are a number of lifetime limiting factors - Uncertainty is due to tip performance (e.g, How fast does it erode?). Goal is source lifetime equal to or better than from existing electronic neutron sources

Q: Have you published research results for this work?

A: Work published - A. Persaud, S.J. Park, J.A. Liddle, T. Schenkel, J. Bokor, I.W. Rangelow, "Integration of Scanning Probes and Ion Beams", Nano Letters, 5(6)1087-1091, 2005.

\section{2:00-1:30 Lunch}

\section{1:45-2:15 "Piezoelectric Transformer Neutron Generator (PTNG)" Speaker: Dr. Gregory Dale, Los Alamos National Laboratory}

\section{Key Points:}

- Goal is to build and demonstrate an integrated neutron source and power supply as an alternative to radioisotope neutron generators used in the well-logging industry

- Utilize D-T fusion reaction-fuse isotopes of hydrogen together in a sealed neutron tube

- Beam of D or T ions is accelerated through a potential of $100 \mathrm{kV}$ and directed onto a metal halide target

- Export of sensitive technology is nominally controlled by both the Department of Commerce under Export Administration Regulations and the State Department under International Traffic in Arms Regulations (ITAR)

- ITAR applies to technology that is militarily significant

- The PTNG utilizes a field ion desorption source for the creation of ions. This source benefits from its inherent compact size and lack of ancillary components such as heaters and ion focusing systems 
- We will couple the field ion desorption source to a piezoelectric high-voltage generator which is more compact than the traditionally used methods of high voltage generation

- Piezoelectric high voltage generator is $5 " \times 5 "$ in size with 1 Gohm output impedance

- Piezoelectric materials are able to convert mechanical signals into an electric potential and vice versa

- Piezoelectric HV power supply - Using analytical models, we are currently exploring different geometries

- Tip design - Utilize sharp emitter tips of silicon currently being fabricated by wet etching process anisotropic etching and isotropic etching

- Sharp tips have higher field enhancement, but rounded (ball) tips may have higher emission area and more uniformity

- Monte-Carlo N-Particle (MCNP) radiation transport code is widely used for modeling and simulation of well logging tools and the impact of surrounding rock formations.

- Analysis of well logging data is a complex inverse problem and, in part, relies on historical data bases to aid interpretation of the data

- Neutron source comparison - neutron energy spectra for AmBe and D-T are quite different

- Source performance modeling - Predict the performance of the well logging tool and compare to other neutron sources used in industry

- Status

- Functional requirements of the major system components have been specified

- $100 \mathrm{kV}$ piezoelectric transformer has been designed. Currently working towards verifying 100 $\mathrm{kV}$ output before the end of the CY 2010.

- Working towards demonstrating neutron production with the PTNG before the end of CY 2010.

- Risk Mitigation

- Develop first source using a D-D reaction to avoid the costs associated with tritium handling during development. Tritium can be added to subsequent devices to increase neutron yield and energy.

- Several potential source topologies will be investigated for use with the piezoelectric transformer (field ion desorption source, flashover ion source, sealed tube neutron source)

- Plans for FY11 - Complete preliminary PTNG well logging tool design. Demonstrate neutron production with the PTNG. Publish test report on patterned ion source and hydrogen loading. Benchtop prototype of the PTNG sent to LANL for evaluation

\section{Questions:}

Q: Do you think you can increase D-D neutron generation by a factor of 100 ?

A: Maybe

Q: Regarding the pulse output, what are the "on" and "off" times (duty cycle)?

A: We have not performed any time dependent modeling

Q: What are the MCNP predictions for neutron generation? 
A: The MCNP model is mainly for AmBe sources

Q: Please confirm that your new contribution is the piezoelectric transformer technology.

A: Yes, that is correct

Response to answer: Only 20\% of what you are doing is new research work (the percentage should be higher)

\section{2:15-2:45 “Compact, Inexpensive, and Robust Low-Energy LINACs (Phase II SBIR Grant FY2010)" \\ Speaker: Dr. Pedro Frigola, Radiabeam Technologies}

\section{Key Points:}

- RadiaBeam Overview

- Manufacture accelerator components and systems

- Develop new accelerator technologies for commercial applications

- Ongoing projects for NNSA

- The "Radiatron" - a high average power FFAG (Fixed Field Alternating Gradient) betatron potential replacement for ${ }^{60} \mathrm{Co}$ in medical product sterilization

- "MAP” (Micro Accelerator Platform) - a high gradient laser-powered dielectric accelerator

- The "Rapitron" - 1 kHz rep rate dual energy linear accelerator (linac)

- Motivation

- High activity radioisotope sources pose a high risk for accident or use in a dirty bomb

- There are some kilovolt x-ray irradiators on the market, however they have not been widely adopted due to low x-ray output

- MicroLinac - small, inexpensive X-band linear accelerator

- Primary innovation is to use a very low power inexpensive X-band RF/microwave source

- X-band $(9 \mathrm{GHz})$ allows linac to be small, versus conventional S-band linacs operating at $3 \mathrm{GHz}$

- High power X-band sources are expensive and hard to find

- MicroLinac is designed to use commonly available technology

- $1 \mathrm{MeV}$ version designed to replace ${ }^{192} \mathrm{Ir}$ for industrial radiography

- SLAC (Stanford Linear Accelerator) prototype can only reach $500 \mathrm{keV}$

- Standing wave Pi-mode design; two sections

- Direct adaption of SLAC's RF design but errors have been corrected

- Designed for high energy

- $2 \mathrm{MeV}$ compact electronic blood irradiator

- Designed to produce equivalent dose rates and uniformities similar to ${ }^{137} \mathrm{Cs}$ irradiators

- Required complete redesign - pi/2 mode, side coupled, standing wave

○ LINAC RF parameters 
- $\mathrm{X}$-band pi/2 mode standing wave, peak RF input power is $220 \mathrm{~kW}$

- Industrial Partner

- J.L. Shepherd and Associates (JLSA)

- JLSA will integrate the MicroLinac into a fully functional blood irradiator system and take charge of the FDA approval process

- JLSA investment in project is $\$ 500 \mathrm{k}$ in value

- Future work

- 3-4 MeV MicroLinac replacement of ${ }^{60} \mathrm{Co}$ for use in radiography and gamma backscatter (density) measurement in borehole well logging

- Requirements - must fit in a 4" diameter, low power consumption, must resist high temperature and vibrations, exhibit high reliability and beam dose stability. Density measurements require stable accelerator beam (both energy and beam current). Linac must be competitive with currently used sources. These requirements can be met with the MicroLinac platform

- RadiaBeam has been developing a novel fabrication process - Electron beam melting (EBM) is an additive manufacturing (AM) process employing layer methods to allow for virtually any geometry to be realized

- ARCAM EBM (http://www.arcam.com) - produces fully dense parts by melting metal powder using an electron beam

- EBM advantages -low production cost, fast development and lead time, superior performance features (internal, conformal cooling channels, nearly monolithic assemblies)

- Material Development - optimized copper process parameters

- Obtained as EBM densities of $8.84 \mathrm{~g} / \mathrm{cm}^{3}$ fabricated several prototype parts with internal cooling

\section{Conclusions:}

- Radiabeam is planning on developing higher energy MicroLinac versions to replace ${ }^{60} \mathrm{Co}$ sources used in borehole logging density measurements

\section{Questions:}

Q: How much will this cost?

A: $\$ 120 \mathrm{~K}$ source.

Statement from Chevron: Why do you assume we need 3 or $4 \mathrm{MeV}$ ? ... All I need is a $1 \mathrm{MeV}$

Q: What is the required power input for the MicroLinac?

A: $220 \mathrm{~kW}$ and double that for the $3-4 \mathrm{MeV}$ 


\section{2:45-3:15 “Compact Neutron/Gamma Generators for Well-logging (Phase I SBIR Grant FY2009)" Speaker: Dr. Ka-Ngo, Berkion Technology}

\section{Key Points:}

- Purpose - Replacing radiological sources such as ${ }^{137} \mathrm{Cs},{ }^{192} \mathrm{Ir}$, and ${ }^{60} \mathrm{Co}$ with accelerator-based gamma generators

- Approach - Use compact electrostatic accelerator to produce monoenergetic gammas via nuclear reaction processes such as $\mathrm{D}+{ }^{6} \mathrm{Li} \rightarrow{ }^{7} \mathrm{Li}+$ gamma $(478 \mathrm{keV})$.

- Collaborated with Sandia

- Operate in continuous or pulsed mode, sealed tube arrangement, neutron/gamma output can be optimized by using the proper configuration

- Source requirements for well logging - Immunity to vibration and high temperatures, small foot print, low power consumption, proper neutron/gamma yield and energy spectrum

- An electronic neutron/gamma generator consists of three main components:

- Ion source - Penning, RF, microwave, or field emission (advantage by eliminating power requirement)

- Accelerator - (D+) $100 \mathrm{keV}$ electrostatic accelerator column

- Beam target -solid lithium target or ion beam driven target

- Neutron filter

- Advantages

- RF driven plasma source can achieve high D+ ion percentage and high current density

- Can be operated with high or low RF input power to achieve long life

- Being used routinely to produce D-D fusion neutrons

- Operate with a mixture of $\mathrm{D}_{2}$ gas and lithium vapor for $478 \mathrm{keV}$ gamma production

- Accelerator column

- Employ a single gap $100 \mathrm{kV}$ electrostatic accelerator column for continuous operation

- Use a high voltage pulser or a low voltage extraction electrode for pulsed operation

- New pyroelectric accelerator system $(\mathrm{V}>300 \mathrm{kV})$ is begin developed for gamma production at Sandia National Laboratory

- Developing an electronic mono-energetic gamma source to replace and $\mathrm{Cs}$, Co, and Ir.

- Lab prototype is assembled and being tested, pyroelectric crystal generates high voltage. The crystal is heated/cooled by a dielectric fluid. Voltages up to $135 \mathrm{kV}$ were measured when the crystal was rapidly heated by 55 degrees.

- Advanced high voltage power system accelerates ions onto gamma production target 
- Beam target design - Beam-driven Ti target is a proven technology for D-D, D-T, or T-T production. We have investigated a solid Li target for gamma production.

- Ion beam-driven Li target for gamma production

- Berkion RF-driven ion source mounted on the magnetic deflection mass spectrometer for ion species analysis at Sandia

$\circ$ Dimension (less than $10 \mathrm{~cm}$, height $75 \mathrm{~cm}$ )

- Neutron filter for $\mathrm{D}+{ }^{6} \mathrm{Li}$ gamma generator

- Neutrons produced along with ${ }^{7} \mathrm{Be}$ can be converted into $480 \mathrm{keV}$ gammas by surrounding environment

- Ultra-compact electronic neutron/gamma source for well logging - $8 \mathrm{~W}$ power requirement, $3.5 \mathrm{~cm}$ in diameter

- There are other reactions besides D-D, D-T, and T-T to produce neutron spectra similar to AmBe sources

- For a source size of $75 \mathrm{~mm}$, we can produce about $10^{8}-10^{9} / \mathrm{sec}$. (Comment from well logging industry - "We are accustomed to neutron fluxes of $10^{11} / \mathrm{sec."}$

- Challenge - To find and optimize the proper nuclear reaction to generate gammas and neutrons in the appropriate energy ranges.

\section{Conclusions:}

- Possible to replace radiological sources in well logging by using either RF-driven or field-emission type neutron/gamma generators

\section{3:30-4:30 "Panel Discussion" - All speakers}

Q: (directed to government speakers) "So the message is that AmBe sources will not be going away but regulation is focused on making it safer?"

A: (from NRC speaker) "As long as NRC does not perceive a current threat, NRC will not eliminate the source."

A: (from EPA speaker) "According to the Energy act of 2005, the federal government will have to report to Congress on progress in the source replacement area (via an interagency task force). We need to make sure industry has what they need before we can implement any new source technologies."

Comment from industry: "We probably will not see any new regulations until some catastrophic event like the Gulf of Mexico oil spill disaster....such an accident is going to cost a lot more than making regulations ahead of time...It is going to take 10-20 years to implement these new source-less well logging technologies. We are fearful that the AmBe sources will be so highly regulated that they will be unavailable before the end of the 10-20 year development period and it will be hard for oil companies to do their jobs."

Q: "The SBIR process appears to be the way to get the new radiation source technologies implemented, is this correct?"

A: (Pedro Frigola, Radiabeam Technologies) - "After you have a prototype, companies and investors are more likely to have interest."

Comment from industry(Baker Hughes): "What you need to do is make new processes and new ideas... we do not need you to make a logging tool....chemical sources right now are fully reliable, smaller and better (cannot turn "on" and "off" is one disadvantage)." 
Comment from industry: "The current requirements for AmBe are in the thousands of curies... The only Am is available from Russia. There are electronic source solutions but they are not going to happen tomorrow and development is going to be expensive. Need guidance not on eliminating but minimizing the use of $\mathrm{AmBe}$ - -there are immediate needs because some countries will not allow these nuclear sources (neutron or gamma) due to accident liability."

Comment from industry (Baker Hughes): "We still need the ${ }^{137} \mathrm{Cs}$ source for density measurements even if we can reduce AmBe."

Comment from industry (Chevron): "We would like a gamma-gamma $1 \mathrm{MeV}$ tool for density. The National Academy of Sciences report did not focus on replacement of ${ }^{137} \mathrm{Cs}$ but only on AmBe."

Q: "Isn't ${ }^{252} \mathrm{Cf}$ an alternative to $\mathrm{AmBe}$ ?"

$\mathrm{A}$ : "You can't produce enough...one government agency says use ${ }^{252} \mathrm{Cf}$ and another government agency says they have stopped producing it. This is the same situation we presently have with ${ }^{241}$ Am."

Comment from industry: "We need to think globally not just within US borders...the level of paperwork for isotopic sources costs more than the isotopic source."

Comment from industry: "Well logging sources are most unlikely to be dispersible through a "dirty bomb"."

Comment from industry: "Inhaled alpha-emitting material is very damaging... only need to have the rumor of this happening for this to be a serious event."

Comment from industry (small independent well logger): "We don't have the resources to find alternative technologies...we are professional people and shouldn't be compared to the "medical" people who use sealed sources." 
Thursday, October 28, 2010

"Emerging alternatives to Nuclear Well Logging"

8:00 Continental Breakfast

8:30-9:15 "Radioactive Sources in the Petroleum Industry: Applications, Concerns and Alternatives"

Speaker: Dr. Ahmed Badruzzaman, Chevron

\section{Key Points:}

- Nuclear Sources in Petroleum Industry

- Upstream

- Reservoir Characterization - Exploration, development

- Reserves estimation

- Nuclear methods used in a suite of instruments (use chemical radiation sources mostly)

$\circ$ Monitoring secondary and tertiary production

- Remaining oil/gas

- Complex production conditions: nuclear primary -use neutron generators mostly

- Downstream - gauges

- Key petrophysical parameters -

- Porosity - Determine formation's potential for holding oil/gas- - estimate reserves volume (neutron and photon sources, acoustic, NMR for liquid only)

- Saturation - estimate hydrocarbon fraction (use electrical and/or nuclear methods)

- Permeability -ability for oil to flow (use core samples)

- Lithology - shale and elemental composition

- Photon based (gamma-gamma) formation density is the most important nuclear measurement

- Reservoir characterization: Shale identification, porosity, and saturation (example log plots)

- Nuclear logging measurements

- Nuclear measurements are very shallow (18 inches)...must correct for well-bore effects

- Statistical measurement - For good measurement precision you need a large number of neutrons.

- Typically use dual-detector neutron porosity and photon tools (near and far detectors)

- Sample Petroleum Industry Sources

- Neutron porosity - ${ }^{241}$ Am241-Category 2-3..potential for death/permanent injury

- Density - ${ }^{137} \mathrm{Cs}$ - Category 3 ...permanent injury

- Vulnerabilities due to sources

- Risks with radioactive sources used in petroleum industry

- Used securely in tools, transported in shielded containers 
- Mobile in remote locations, transported across the world: over 9,000 sources in the field

- Source Security - Radiation dispersal devices (RDDs) possible. Speaker gave testimony before US Senate after the 911 tragedy

- US National Academy of Science report

- Government of Nigeria requirement on logging sources (2003)

- AmBe source in neutron porosity tool went missing but was later found, trail not clear

○ Could have had RDD potential-governments concerned

- California $-{ }^{137} \mathrm{Cs}$ source in a density tool breached down hole in a well at $1800 \mathrm{ft}$. (contaminated hole)

- Tool stuck breached source--bad news and expensive long term problem

- Contaminated dirt and mud disposed of using licensed vendors, under appropriate regulations

- Surrounding wells shut down, lease owners compensated

- State mandated 300 year monitoring program

- $10 \%$ of radioactive material recovered

- Costly - lost production, long term monitoring, potentially contaminated reserve

- Operators need in-house protocols for source safety and security. Cannot entirely rely on vendor protocols

- Recommendation on Operator Protocols

- Clear protocols to receive, utilize, and hand over sources to vendors

- Establish clear decision chain and training

- Each business unit needs to designate a key contact to deal with source issues

- Alternative to nuclear logging sources

- Life without nuclear sources (lack of nuclear data has an impact on the reserves estimate)

- NMR, acoustic, gravity methods are alternatives to nuclear measurements

- Alternative nuclear sources (e.g., electronic sources)

- NMR Characteristics

- Works well in most formations with water or regular oil

- Porosity low with gas - need density or sonic methods--cannot estimate porosity without density and neutron porosity

- Acoustic Characteristics

- Sonic velocity responds to both porosity and pore fabric

- Not useable in gas

- Works well in limestone 
- Impact on reserves

- Uncertainties are between 400-800 million barrels

- Neutron Source Alternatives

- Upstream

$\circ$ Density - gamma-gamma is most accurate porosity measure - no commercial alternative to

${ }^{137} \mathrm{Cs}$, less dangerous for RDD, but can contaminate reservoirs if breached

- Pseudo density - inelastic scattering - developed but not as accurate

$-\quad$ Use ${ }^{252} \mathrm{Cf}$

- Issues with alternative sources - different source properties - peak energy, different physics new calibration required, reliability uncertain

- Interpretation - near-to-far ratio of a dual detector device with source variation - measured porosity

- ${ }^{252} \mathrm{Cf}$ neutron spectrum is similar to AmBe. High energy D-T neutron sources require greater near-to-far detector spacings

- D-T tool designed in 1980's

- To achieve full user utilization of a new neutron tool

- Vendor must build hardware, test in well, and perform Monte Carlo simulation

- User performs field trial and modeling work

- Takes 10-20 years to deploy a new tool

- Monitoring through complex boreholes -- use D-T neutron sources - electromagnetic tools or NMR will do wonders

\section{Conclusions:}

- Radioactive sources are critical to petroleum industry, non-nuclear alternatives will not do

- Current sources pose RDD and contaminated hazards -

- Where do we go from here?

- National labs and source vendors must advance source research

- Service companies - design new tools - major ones can do it on their own, smaller ones will need support

- Oil companies - identify and address measurement and interpretation issues

- Challenge offers the opportunity for a quantum leap in nuclear logging technology

- Shall we take it up? 


\section{Questions:}

Q: "You show that there is a lot of error (400-800 million barrels) in these logging alternatives tell me more about this."

A: "Oil companies need to know results that they are getting are correct."

\section{9:15-9:45 "Seismoelectric Well Logging" Speaker: Dr. Richard Clarke, Groundflow Ltd}

\section{Key Points:}

- Groundflow Ltd conducts USA seismoelectric sounding surveys -

- Types of seismoelectric response -

- interface response - signal

- seismic p-waves compress and stretch the porous, permeable rock matrix and contained mobile fluids at different rates (Biot theory)

- ions in the fluid become separated from their counterparts bound to pore surfaces causing charge separation at seismic frequencies

$\circ$ in homogenous rock, a counter-current through the conductive pore fluid restores equilibrium and no signal is radiated

- at bedding planes and other plane interfaces there may be a change in properties causing a net charge separation... this perturbs the EM field and the perturbation radiates from the interface

- the interfacial signal is typically modeled as a bundle of dipoles within the first Fresnel zone and normal to the interface but NOT necessarily vertical

$\bigcirc$ the horizontal component of the field perturbation at the surface is strongly focused EXACTLY at the shot point

- Seismoelectric sounding model - first Fresnel Zone...horizontal component of dipole field EM signal.

- Focusing of interface response (Mikhailov et al. 1997)

- Co-seismic field - noise

- Direct field - noise

- Lorentz field - noise

- Practical considerations

- Wytch Farm Oilfield, UK

- Reference Hogg et al, 1999

- Buffalo gun source with two radial dipole antennas

$\circ$ Less than $0.5 \mathrm{~m}$ from source

- One signal inverted to display dipole symmetry, otherwise no stacking or processing

- Signal/Noise ratio 20:1 
- Water table, Eocene aquifer, and oil bearing sandstones produce the signals but everything else provides no signal

- Signal is focused at a 3 meter offset

- Focused water table signal

- Cherhill data taken with paired radial dipoles, no stacking or processing

- Note that the co-seismic response is trivial when not artificially emphasized by processing

- How seismoelectric logging works

- A seismic source radiates at 2 or more frequencies in liquid filled holes

- The pore fluid moves relative to the matrix where it is able to causing charge separation.

- Remotely detectable signals are radiated from interfaces and are focused back to the seismic source

- Signal bandwidth is proportional to fluid mobility - controlled mostly by viscosity and permeability

- Signals are detected by dipole antennas placed close to the source

- Signal amplitude is inversely proportional to pore fluid conductivity

- Seismoelectric logging is done at normal speeds with a non-contact tool using standard components and is both safe, rugged, and compatible with other devices and there are no unusual pressure or temperature restrictions

- Electro-Kinetic Logging (EKL) sonde

- Material - copper (better electrode), battery driven, serial decoder, and laptop, hand winch, electrode support with plastic centraliser

- Seismoelectric logging source behavior

- Limits the investigation to 1-2 meters

- Logging at higher frequencies $(>100 \mathrm{kHz})$ gets a little more difficult

○ Typically use $60 \mathrm{kHz}$

- Tool run in air - there is no detectable pickup from the shielding

- Stationary seismoelectric log response - lots of chatter/noise

- EKL sonde transducer needs loading - sine and cosine gives different responses

- Seismoelectric log vertical resolution modeling

- Model suggests a resolution of about $1 \mathrm{~m}$

- Pore fluid conductivity rise reduces EKL log amplitude

- Shripney borehole, Cretaceous chalk with seawater incursion (amplitude drops off)

- Note that his early version of the EKL log uses a $42 \mathrm{~Hz}$ square wave and its $3^{\text {rd }}$ and $5^{\text {th }}$ harmonics...not recommended but still workable 
- Logging examples

- EKL log in plastic cased hole - can see the cased hole perforations

- OYO Rock Borehole test

- Padgate 4 EKL example

- Carlton 2 example

\section{Conclusions:}

- Qualitative aid to recognition of hydrocarbon bearing intervals (gas)

- Quantitative evaluation - as part of combination log suite of:

- Reservoir permeability

- Pore fluid viscosity (oil, water, gas)

- Pore fluid conductivity

- Development Path

- Low cost, rugged and compatible using standard technology

- Low power processing, and low signal baud rate requirement

- Existing design and trials data available

\section{9:45-10:15 "Borehole Gravity for Density Measurements" Speaker: Dr. Terry Hagiwara, Aramco Services}

Key Points:

- Need density logging to estimate formation porosity

- neutron porosity $(\mathrm{AmBe})$

- pulsed neutron (D-T)

- NMR porosity

- Borehole gravity measurement

- Absolute - free fall measurement

- Pendulum measurement

- Spring: Hook's law

- Why?

- Need a formation density measurement (not electron density derived from gamma-gamma scattering)

- Deeper depth of investigation

- Insensitive to near borehole damage

- No environment effect, including tool itself

- Multiple depths of investigation 
- Easy straightforward interpretation

- Application examples

- Formation density measurements - porosity

- Deep-look (remote sensing)

- Monitoring especially identification of gas versus fluid

- Gravity of an infinite layer-- Difference measurement assumes that ground above and below are the same

$\circ$ Measure gravitational acceleration constant, $g$, at two points. Calculate density of layer between two points

- Measurement easy (tool itself very complicated)

- How robust is gravity-determined density?

- Stationary measurement? What is the required measurement time?

- Vertical resolution? 1-2 feet

- Where is the tool?

- Current technology

- LaCoste and Romberge, near vertical hole only, large diameter 4.1", stationary measurements, depth control difficult

- Gas Cone - density log may indicate lowering of GOC. Can we detect and differentiate between oil/gas/water?

\section{Conclusions:}

- Borehole Gravity = Deep Density

- True density measurement without environmental/borehole effect

\section{Questions:}

Q: What is the logging speed?

A: Slow logging speed is one of the big negative factors... stationary measurement is needed...This is not an alternative to nuclear logging, but rather an additional tool

\section{0:15-10:30 Coffee Break}

\section{0:30-11:15 "Electronic Neutron (Radiation) Sources" Speaker: Dr. Allen Gilchrist, Baker-Hughes}

\section{Key Points:}

- Neutron generators

- Deuterium gas is boiled off the gas reservoir

- Electric and magnetic fields in the ion source create a plasma of ions along the axis of the anode

- Ions are accelerated towards the target which contains tritium 
- X-rays - photons generated in electro-mechanical devices - continuous energy spectrum, maximum energies up to about $500 \mathrm{keV}$, higher energies are possible

- Gamma rays -

- Other types of electronic radiation sources

- Gamma rays and x-rays are both high-energy photons

○ X-ray Tubes/generators

- Electrons are accelerated toward a target

- Electrons strike the target producing X-rays

- Depending on the electron energy and the target both a continuous spectrum and characteristic lines can result

- Low efficiency means significant power requirement and heat production

- X-ray generators

- Accelerators

- Linear accelerators come in a variety of forms

- DC HV guns

- RF guns

- Multi pass accelerators

- Cyclotrons

- Synchrotrons and betatrons

- Neutron Porosity

- It is currently possible to use pulsed neutron generators as sources in neutron porosity tools.

- Best results are achieved if the tools are specifically designed for borehole measurements

- Conventional gamma-gamma density tools

- Gamma-gamma density measurements depend on interaction between gamma rays and electrons or atomic nuclei within the formation

- Three types of interactions- - photoelectric effect, Compton scattering, and pair production

- Gamma Ray Absorption Effects - energy range .1-10 MeV for most abundant elements in rocks, the Compton-effect dominates, for lower energies the photoelectric effect is important

- Single detector gamma-gamma density - source detector (high density material shield) and material

- Modern multi detector density tools - allow for compensation for mudcake, standoff, or other effects

○ Single energy source $\left({ }^{137} \mathrm{Cs}-663 \mathrm{keV}\right.$ gamma rays $)$

- Adequate shielding

- Critical issues with accelerator based density tools

- Continuous energy distributions

- Bremsstrahllung continuum 
- Adequate shielding of source- difficult to achieve at higher energies

- Significant power requirements and heat loading issue

- Poorly defined geometry

- Distributed sources or equivalent issues due to energy differences

- Geometrical difference with pulsed neutron sources

- With a pulsed neutron source - gamma rays are being produced..volume impacted is much larger and poorly defined ("all over the place") in addition that the gamma rays are at different energy levels

- Differences with accelerator systems

- Assuming we can overcome the power and heat problems

- Needed Technologies

- Photon generators that will

- Be deployable in a borehole

- Produce sufficient numbers of photons of usable energies while fitting within an achievable power budget

- Operate reliably at the temperature, shock and vibration levels encountered in logging

○ New measurement methods that will

- Account for the differences in source energy distributions

- Adequate shielding

- Optimum detector spacing?

- Pair production?

- Photoelectric effect?

\section{Conclusions:}

- ${ }^{137} \mathrm{Cs}$ source density measurement is the international standard to determine porosity

- Formation density and neutron porosity together provide mineralogy information and hydrocarbon type

- Current sourceless systems (e.g., NMR) are not accurate enough

- True sourceless density measurements will require step change and technology advances in several areas

\section{Questions:}

Comment: NaI, CsI are two scintillation materials for photon detection, but there are other detectors that are more proprietary

Comment: We all need to think outside the box...

Q: Does the pulsed neutron source give you the same quality information as the traditional AmBe source?

A: Yes, but when you get above the normal (AmBe) energy range you get a lot more information that is not "historic". Need to mentally move around it -- pulsed neutron logs look different from the "historic" logs using AmBe sources which today are most widely used

A: Cost issues: 
- $\mathrm{AmBe}$ - price has gone up considerably $(\$ 20 \mathrm{~K}$ to now $\$ 100 \mathrm{~K})$. However this source is more reliable and lasts longer

- Neutron generators - have not changed much (lifetime - 100 to low thousands of hours of operation). Need neutron generator to operate $24 / 7$ - must carry spare D-T source to the well site

Q: Are there concerns over tritium release when neutron generators get lost or stuck in hole?

Comment: We have never had a breach of an AmBe source but breach of ${ }^{137} \mathrm{Cs}$ source happens once every 10 years.

\section{1:15-12:00 “Thermal Neutron Porosity Using Pulsed Neutron Measurements" Speaker: Dr. David Madio, Schlumberger}

\section{Key Points:}

- Key Neutron concepts (D-T source $-14 \mathrm{MeV}$ )

- Hydrogen sensitivity

- Slowing down length $\left(\mathrm{L}_{\mathrm{s}}\right)$ is a measure of hydrogen content. The higher the neutron energy loss rate, the shorter the $\mathrm{L}_{\mathrm{s}}$.

- Capture by nucleus

$\circ \quad$ Neutron capture cross section, $\sigma$

- Basic compensated neutron tool (CNT) design

- Neutron source $-\mathrm{AmBe}$ or portable neutron generator

○ Two ${ }^{3} \mathrm{He}$ detectors - thermal and epithermal

- Near/far count rate ratio - transform to neutron porosity

- Motivation - traditional thermal neutron porosity logs (vast majority of neutron logs - use AmBe)

- Increasing heighted concerns for security and environment

- Reduced availability

- Radiation source licensees do not bear the full cost of liabilities related to misuse of sources and disposal of americium sources

- Portable neutron generators (PNG) shows promise to address these issues

- PNG-based neutron porosity tools are in use today

- Source energy is different than AmBe

- Neutron detectors may be different

- Detection of epithermal neutrons may improve petro-physical accuracy

- Different from traditional AmBe based measurements (key point)

- Goal

- Thermal neutron porosity from PNG measurements

○ Approach:

- Use available PNG tools

- Algorithms based on physics 
- Near/Far (N/F) Ratio vs. Slowing down Length

- Thermal neutron near/far ratio primarily a function of $\mathrm{L}_{\mathrm{s}}$

- Sigma contributes to scatter about limestone trend line

$\circ$ Water $-\mathrm{L}_{\mathrm{s}}=7.2 \mathrm{~cm}$, Limestone $-\mathrm{L}_{\mathrm{s}}=24 \mathrm{~cm}$

- Comparison to Monte Carlo modeling

- Evaluate near/far ratio

- Higher porosities show bigger difference

- Density correction improves agreement

- Converting from PNG to AmBe

- Area of interest occurs at the most common porosities (10-20 porosity units)

- Density and slowing down length product can correlate the PNG results with the AmBe results

- Algorithm

- PNG (Epithermal neutron Porosity) - N/F ratio - Slowing down length - sigma/density slowing down length $(\mathrm{AmBe})-\mathrm{N} / \mathrm{F}$ ratio (density correction - Thermal neutron porosity $(\mathrm{AmBe})$

- Validation - 25 wells, water and oil-based muds, fresh to salt salinity, different lithologies

- Examples from : Middle East Limestone (good agreement), shaley sand - good, carbonate good, Ten well validation - statistics worsen when you get in higher porosity

\section{Conclusions:}

- New PNG based thermal neutron porosity algorithm

- Based on nuclear physics and modeling

- Successful in validation tests

- Shows good correlation between AmBe and PNG

\section{Questions:}

Comment: You now have a time based measurement as opposed to a continuous neutron source.

Comment: If you start with epithermal measurement (possible to make corrections) but start with good corrections from the start

Q: What happens when you use D-D instead of D-T reaction?

A: The process should take you from neutron space to another neutron space.

\section{2:00-1:30 Lunch}




\section{1:30-2:00 "Thermal neutron porosity measurements using a pulsed D-T generator in LWD and Wireline" \\ Speaker: Dr. Chris Stoller, Schlumberger}

\section{Key Points:}

- Thermal neutron porosity

- Purpose: Determine the liquid-filled pore volume

- Hydrogen content of a formation determines the slowing down length, $L_{s}$

- Place detector at distance from the neutron source comparable to $\mathrm{L}_{\mathrm{s}}$

- Comparison between LWD tools - The final porosity answer using D-T and AmBe neutron sources must agree

- Schlumberger AmBe tool: ADN6

- Schlumberger D-T Tool: EcoScope6

- Thermal neutron porosity measurement

- Single detector count rates: large environmental effects (borehole size, fluid, standoff, salinity.)

- $\mathrm{AmBe}(\mathrm{LWD})$

- AmBe neutron energy spectrum 0-11 MeV

- Continuous Output $\left(4 \times 10^{7}\right.$ neutrons/sec)

- Average neutron energy $-100 \mathrm{keV}$

- Slowing down dominated by hydrogen

- D-T Generator (LWD)

- Typically operated in pulsed mode $\left(10^{9}\right.$ neutrons per pulse)LWD and 2-3x $10^{9}$ (wireline)

- Does not provide as stable of output as AmBe

- Energy spectrum $-14 \mathrm{MeV}$

- Reduced dynamic range (about $50 \%$ of $\mathrm{AmBe}$ )

- Slowing down of fast neutrons

- First rapid energy loss by $\mathrm{H}+$ and inelastic collisions $(1 \mathrm{MeV})$

- No inelastic interactions below $1 \mathrm{MeV}$

- Principal Effects when slowing down neutrons

- Elastic scattering cross sections of neutrons

- Hydrogen has the biggest effect

- Inelastic Scattering cross section of neutrons

- $\mathrm{Al}, \mathrm{O}, \mathrm{Fe}$ are comparable to $\mathrm{H}$ collision (AmBe neutrons play a large role due to lower neutron energies) 
- Neutron Transport

- Effect of $\mathrm{H}$, density, and sigma

- Measure neutron flux at the detector

- Correcting for "Density"

- Need to match the density effect with both AmBe and D-T sources

- Assume that sigma (neutron capture cross section) can be neglected

- Count rate is inversely proportional to distance from source and hydrogen index

- Porosity Response

- Near/Far Ratios

- Reduced dynamic range in near/far ration with D-T

- $\mathrm{Al}_{2} \mathrm{O}_{3}$ is used to simulate shale (density is high, sigma is small so it does not absorb neutrons as much)

- Formation shows larger shale effect than in AmBe

- After full density correction (D-T) - Near/Far Ratios

- D-T enhanced dynamic range

- Aluminum oxide formation shows no effect when applying the density correction

- Need to do a partial correction for density to match TNP (thermal neutron porosity)

- Example... Shale agrees very well. Gas - agrees well

- Density measurement is needed to do the density correction

- Gamma-gamma density (not quite source-less due to Cs-137)

- Neutron-gamma density (combined neutron gamma transport is very complex)

- Does not need high accuracy

$\circ$ Density needs to be accurate to about $0.1 \mathrm{~g} / \mathrm{cm}^{3}$

\section{Conclusions:}

- The D-T based measurement can deliver the following

- Accurate hydrogen index measurement (similar to APS-Accelerator Porosity Sonde)

- Accurate thermal neutron porosity measurement

- Same shale effect as AmBe-based neutron porosity tool

- Same lithology effect as AmBe-based tool

- Higher precision or higher ROP (rate of penetration) with same precision

- Instead of trying to match the source spectrum, match the response

- For this approach a density measurement is required

- Gamma/gamma and neutron/gamma 


\section{Questions:}

Q: In the open hole case you typically know your density, how does this work in cased holes?

A: In a cased hole - always try to use pseudo density (but doesn't need to be highly accurate to make the corrections since they are not the desired outcome)

Q: For gas is there any difference in the precision?

A: No, you don't need to have high accuracy and precision for the neutron/gamma measurement would increase uncertainty a little.

Q: David Madio's and your approach are slightly different?

A: Yes, both could be applied.

Q: Regarding making assumption of density in cased holes -- the influence of density is

omnidirectional since you have gammas coming in all directions...Are all the detectors scintillation or ${ }^{3} \mathrm{He}$ ?

A: There are two scintillation detectors and two ${ }^{3} \mathrm{He}$ neutron detectors - the scintillation detectors are used for spectroscopy

Comment: The neutron gamma density has deeper penetration, but since it is deeper it will see multiple layers unlike gamma/gamma density

\section{2:00-2:30 "NMR and Acoustics - An Integrated Solution for Sourceless Porosity" Speaker: Dr. Songhua Chen, Baker-Hughes}

\section{Key Points:}

- The combined NMR/acoustic approach is truly sourceless (green nuclear)

- Porosity estimation by NMR log

- Principle of NMR measurements

- Proton NMR Logging

- Signal strength is proportional to proton density in sensitive volume

- Sensitive to fluids in pore space only

- Insensitive to protons in minerals in solid rock matrix

- Method is ideal for porosity measurement (i.e., this is a direct measurement of porosity)

- NMR porosity sensitivity

- Equilibrium magnetization $\mathrm{M}_{0}$

- $\mathrm{M}_{0}$ depends on

- Number of nuclei (hence the signal weak for gas)

- Nuclear species

- Static field strength

- Noisier in reservoir than ambient condition

- NMR desktop and logging Instruments

- Two designs : a) Magnets point towards each other (signal contributions from all around the tool axis) and; b) magnets on top of each other which gives you signal contributions from one side

- NMR Porosity Measurement

- Spin echo and $T_{2}$ free induction decay - measure echo amplitude vs time

- NMR porosity Interpretation 
- A time series of NMR signal amplitudes

- Represents fluid relaxation time distribution

- Hydrogen-index Issues

- Salinity - affects water porosity

- Particularly for salt-saturated water

- Invaded mud filtrates

- Formate (much less than 1)

- OBMF-oil based mud filtrate (can be less than 1)

- Salt saturated mud

- Very light hydrocarbons

- Gas and condensates (temperature, pressure, composition dependent)

- High GOR (gas/oil ratio) oil (dissolved gas effect)

- Particularly for depleted wells

- Apparent hydrogen-index issues

- Relaxing too slow

- Pre-polarization magnet required on wireline NMR tool

- Long wait time required for full polarization

- Correctable even if wait time is small with an assumed $T_{1} / T_{2}$

- Relaxing too fast (TE limitation)

- Tar and other low API oils

- Organic matter

- Non-free gas

- CBM (coal bed methane), adsorbed gas, gas hydrates

- Case studies......Where it works and where it does not.

- Examples

- Deep water Gulf of Mexico example - Advantage of low gradient

- Matches core properties

- Fine sands + low gradient separates water and oil on $T_{2}$ spectrum

- NMR porosity in light oil-bearing and tar-bearing zones

- Sensitivity of NMR porosity in low porosity gas well

- NMR measurements in low porosity, low gas saturation wells are not necessarily more inaccurate than high porosity gas well in terms of the absolute porosity unit uncertainty

- High GOR (gas/oil ratio) oil well may require H-index correction greater than 1

- NMR along with acoustic measurement as a source-less porosity tool

- Easy and reliable

- Water and low- to medium-viscosity oil bearing formations

- Mud filtrate flushed gas-bearing formations 
- Acoustic log calibrated by NMR

- Acoustic Porosity

○ Measurements

- Calibration of lithology effect with NMR

- Original RHG (Raymer-Hunt-Gardner) transform for P-wave

- Modified RHG (Raymer-Hunt-Gardner) transform for P-wave

- One-or Two Step procedure for shaley sand formation

- P-wave and S-wave

\section{Conclusions:}

- Porosity derived from NMR log along with acoustic measurement may be adequate for liquid bearing formations as long as quantification of fluid types is adequate

- NRM in low hydrogen-index (HI) or low apparent hydrogen-index fluid bearing formations amplifies the error bar by $1 / \mathrm{HI}$

- NMR calibrated acoustic porosity is a better approach than NMR alone for formation with low HI fluid

\section{Questions:}

Comment: This method would not work in cased holes where lots of measurements are needed

Comment: NMR measurements are run very infrequently compared with neutron measurements

Comment: Not all wells/formations can accommodate this tool

Comment: Drilling engineer does not want to take the time to use this technique

Comment: NMR measurement adds complementary data but would not be viewed as a replacement

Q: What is the porosity accuracy you can get with this method? Can you get this accuracy with pulsed neutron measurements?

A: 2 porosity units (PU). There's no way you can get 1 PU accuracy.

\section{2:30-3:00 "MRIL and Combinations with Other Logs to Obtain Accurate Porosity"} Speaker: Mr. Ron Cherry, Halliburton

\section{Key Points:}

- Applications - fluid filled porosity independent of mineralogy

- Permeability estimate

- 3 Displays of $\mathrm{T}_{1}$ or $\mathrm{T}_{2}$ distributions

- Bins, VDL, wiggles

- Wet zones and repeatability

- LWD $\log \left(\mathrm{T}_{1}, \mathrm{~T}_{2}\right)$ 
- 2D NMR gives simultaneous $\mathrm{T}_{1}$ and $\mathrm{T}_{2}$

- This process assumes formation is wet and the gas exhibits bulk properties with no surface relaxation effect

- Wireline NMR: tight gas - 2 dimensional fluid characterization - Hydrogen index (HI) correction

- 2DFC-T2D (Two dimensional fluid characterization gives $\mathrm{T}_{2}$ and diffusion constant)

- Relaxation time vs. diffusion constant

- NMR vs. nuclear Logs

- NMR - fluid measurement

- No mineralogy effect

- NMR field test data: mixed lithology -

- What is the porosity? Only measures the fluid and the porosity

- What if you want to know about the rock type?

- To convince you it is correct, compare it to density. Nuclear logging is used as a reference for NMR and other measurements (not sure this can be taken away yet)

- Using an acoustic log (as in previous presentation) it is possible to get more accurate values

- Density and sonic

- Synthetic seismic

○ Geomechanics

- Density is the "gold standard" for porosity

- Neutron - good log for cased holes

- NMR logging is slow

- Discussion items

- Chemical sources

- Reliable, small, no power required

- Market direction

- Small tools or LWD - Number of vertical wells isn't changing...horizontal wells are increasing

- How will these wells be logged?

- Tools for hostile environments

- Does the true safety of the sources matter?

- RDD made with logging source is a "story"

- What if a source is stolen?

- Does it make sense to replace neutron sources without replacing the density (gamma) source too?

- Also talking about calibrators 
3:00-4:00 "Panel Discussion" - All speakers

Questions:

Q: What is the message you want to send to NA-22?

\section{Comments:}

- Making new tools is getting more difficult with new types of wells/formations

- AmBe sources are ideal for what we do. We need to start thinking about it. We hope the national labs give us good sources/good hardware.

- Past source security issues did not involve the operator. Well logging industry is very aware of source security issues. We have been dealing with this issue for many years and the problems have not gone away.

- We have to get started looking for alternatives to nuclear logging but it's not going to be tomorrow. These electronic neutron sources will have to be reliable for many years. We need people to start working on these technologies. We need the technology to work in a well environment. Help is needed from the labs by bringing new technology not building tools.

- The thing that struck me was that there are electronic neutron source patents that go back to the 1960s. The technology is not as accurate as it needs to be. May be improvements in ion sources. This needs to come from people outside the industry (service companies). We need to be looking at other ways of doing things.

- Hard to change the gamma source. Linear accelerator (LINAC) radiation sources are more applicable to the LWD. Standoff is a bigger problem too. The challenges are huge.

- With a pulsed source there is a larger dynamic range

- Also need to think about detectors..... not just sources

- Small vendor cannot afford cost of source development. The industry bias is still that if it comes from Schlumberger, then a 2 to 3 porosity unit difference is ok, but if it comes from a small vendor operators are unlikely to trust the data.

- Some say the U.S. government is "picking on well logging". This is not true; the medical field is being looking at too. Government is actively pursuing research in other industries.

- U.S. government political time frame is 2 years, but decisions in the oil industry (and other industries) require much longer time frames. Suggest you apply "cap and trade" and sell source-less logging credits (jokingly).

- The rest of the world is not like the United States; they are attempting to do away with chemical radiation sources altogether. We are getting a push back against chemical radiation source usage in Africa.

- This discussion has been very helpful and would like to pick up the discussion with the labs and smaller companies. If this was easy to do it would have already been done by the small service companies.

- Need a third company that can sell a neutron generator to help the small service companies. 
- Density measurements using gamma sources are going to the biggest challenge to replace with nonnuclear methods.

We will need permeability tools in the future. 


\subsection{Speaker Biography}

\begin{tabular}{|c|c|}
\hline Ahmed Badruzzaman & $\begin{array}{l}\text { Ahmed Badruzzaman leads Chevron's R\&D effort on nuclear logging technology and } \\
\text { on potential use of nuclear energy for steam and process heat in unconventional } \\
\text { recovery. He also teaches and guided doctoral research at University of California, } \\
\text { Berkeley. He was a reviewer of the } 2008 \text { US National Academy of Sciences report } \\
\text { on Radiation Sources and Replacements and has been the principal oil industry } \\
\text { discussant on the issue. Ahmed is a Fellow of American Nuclear Society, a 2006- } \\
2007 \text { Society of Petroleum Engineers Distinguished Lecturer, 2002-2003 Society } \\
\text { Petrophysicists and Well Log Analysts (SPWLA) Distinguished Speaker, and a } \\
\text { winner of several industry awards for his work in nuclear logging. He is the } \\
\text { coordinator of SPWLA Nuclear SIG, an industry technical group the NAS suggested } \\
\text { as a resource to help, technically, with oil industry source replacement effort. A } \\
\text { physicist by education, he earned a Ph. D in Nuclear Engineering and Science from } \\
\text { Rensselaer Polytechnic Institute, Troy, NY, in } 1979 \text {. }\end{array}$ \\
\hline
\end{tabular}

Allen Gilchrist

Bill Rhodes
Dr. Allen Gilchrist is a Technical Advisor in Drilling \& Evaluation Research at Baker Hughes. He started in the oil service industry in 1977, after earning his Ph.D. in physics from Texas A\&M University. During his career, Allen served in several engineering, research, and management roles, with his work being primarily in nuclear tool development. Allen is the author of three academic publications, 25 professional technical papers, eight other articles, and he holds nine patents.

William G. Rhodes III is the Senior Manager of the International Security Systems Group, Sandia National Labs located in Albuquerque, New Mexico. This Group is comprised of 100 staff members and 6 departments dedicated to addressing national security issues involving nuclear and radioactive materials. He has 30 years of experience in the fields of radiation protection, emergency response, and physical security and their application to national security challenges. Bill completed his graduate academic work at the University of Massachusetts at Lowell, and his undergraduate work at Wittenberg University in Springfield, Ohio. Bill is a Certified Health Physicist, a member of the Institute of Nuclear Materials Management, the Health Physics Society, and a Diplomat of the American Academy of Health Physics. He also serves as an Associate Editor of the Health Physics Journal. He has been a member of the American Board of Health Physics Examination Panel for the past 12 years. He has authored or co-authored over 60 technical papers, book chapters, and presentations, and has given numerous technical briefings to Federal, State and other decision-makers and lawmakers.

$\begin{array}{ll}\text { Chris Stoller } & \text { Christian Stoller is a Scientific Advisor and Physics Métier Manager for the Princeton } \\ \text { Technology Center and for the Sugar Land Product Center. Throughout his career } \\ \text { with Schlumberger, he has been involved in the design and testing of many } \\ \text { Schlumberger nuclear downhole tools. Chris obtained his Ph. D. in nuclear physics at } \\ \text { the Swiss Federal Institute of Technology (ETH) in Zurich, Switzerland in 1976. } \\ \text { Before joining Schlumberger in 1986, Chris worked on a variety of phenomena in } \\ \text { nuclear, atomic and applied physics at the Nuclear Physics Laboratory of ETH and at } \\ \text { Stanford University. } \\ \text { David P. Madio joined Schlumberger-Doll Research in } 1997 \text { in Ridgefield, } \\ \text { Connecticut, as a research scientist specializing in nuclear magnetic resonance. Prior } \\ \text { to joining Schlumberger, he worked at the National Institutes of Health on image } \\ \text { artifact analysis and reduction for functional magnetic resonance imaging of the brain } \\ \text { and on a novel approach to gene therapy using MRI temperature mapping to provide } \\ \text { real-time guidance for localized tissue heating using focused ultrasound. He is } \\ \text { currently providing log analysis and experimental physics support for a nuclear } \\ \text { engineering project in Sugar Land, Texas. Dave has earned degrees in physics from } \\ \text { Wesleyan University (BA, 1981) and the University of Pittsburgh (MSc, 1989; PhD, }\end{array}$


1996). He served as a Distinguished Speaker for the Society of Petrophysicists and Well Log Analysts for 2008-2009.

Gregory Dale
Gregory Dale is a project leader in the High Power Electrodynamics group in the
provides engineering and technical leadership to national security projects in the
fields of neutron sources, compact radiography, pulsed power, and accelerators. Greg
received his BS in Nuclear Engineering from the University of New Mexico, his MS
in Nuclear Engineering with a minor in Physics from North Carolina State University,
and a PhD in Electrical Engineering from the University of Missouri-Columbia. Greg
is the PI of the Piezoelectric Transformer Neutron Generator for Well Logging
project as part of the NA-22 Alternative Source Development effort.
Mr. Schwartzel has been providing senior management services to DOE's Global
Threat Reduction Initiative (GTRI) program for the past eight years. As such he has
provided support to the development of program plans with partner countries and
institutions within the United States to implement nuclear and radiological material
protection efforts. Mr. Schwartzel retired from the United States Navy after 23 years
at the rank of Captain, serving his entire career as a Navy SEAL. Mr. Schwartzel
holds a Master of Business Administration degree from National University and an
undergraduate degree in History from Tulane University.
Ka-Ngo Leung Dr. Ka-Ngo Leung is Senior Vice President of Berkion Technology and Professor-In- Residence of the Nuclear Engineering Department, University of California, Berkeley. He has worked at Lawrence Berkeley National Laboratory for 29 years (until January 2006) pursuing alternative energy sources, fabricating innovative microelectronics and medical devices, developing RF-plasma generators and neutron and gamma sources.

Madeliene Nawar I'm an environmental scientist working at EPA for over 25 years. Currently I'm with the EPA Office of Radiation and Indoor Air. Prior positions involved working on a host of regulatory programs developing and implementing environmental standards for safe drinking water and wastewater management, new chemical reviews and pesticides registration, Superfund cleanup, solid waste management and emergency response. In mid 1990s, I spent two years as a senior environmental specialist at the World Bank, Environment Dept, engaged in review and evaluation of environmental impacts of multilateral development projects for transportation, sanitation, urban services, and agriculture, in addition to coordinating seminars for knowledge exchange among the scientists and engineers at the Bank and EPA. And in 2006, I had the opportunity to serve for six months as a Senior Science Fellow at the US Embassy in Amman, Jordan, providing technical assistance to members of the Jordanian Ministry of Environment, at the direction of USAID.

$\begin{array}{ll}\text { Pedro Frigola } & \text { Mr. Frigola is a Senior Researcher and Co-Founder of RadiaBeam Technologies, a } \\ \text { company specializing in electron beam based radiation sources and diagnostics. He } \\ \text { holds a Masters degree in physics from UCLA, and has over 15 years of laboratory } \\ \text { experience in particle accelerator development, technology and experiments in } \\ \text { particle beam physics. } \\ \text { Rachel Browder, is a Regional State Agreements Officer with the US Nuclear } \\ \text { Regulatory Commission, from the Region IV office located in Arlington, Texas. } \\ \text { Ms. Browder is with the Division of Nuclear Materials Safety where she has been a } \\ \text { reactor decommissioning inspector and radioactive materials license reviewer. } \\ \text { Ms. Browder received her undergraduate degree in Physics from Carson Newman } \\ \text { College in TN and Masters degree in Health Physics from IIT in Chicago. In } \\ \text { addition, Ms Browder earned a certification in Health Physics by the American Board } \\ \text { of Health Physics. Prior to joining the NRC in 1999, she was employed in the } \\ \text { nuclear power industry, where she was a Radiation Protection Supervisor. }\end{array}$




Richard Clarke
Richard Clarke, BSc PhD both from Bristol University, UK, in geology. Since 1994 I
heismoelectric survey equipment. Previously I worked for BP Exploration as an
exploration geologist holding several research and management posts between 1970
and 1992. I have extensive operational experience in the USA, the UK onshore and
offshore and in the Middle East and was awarded the Rank prize for technical
innovation in 1988 for the airborne laser fluorosensor. Before that, between 1963 and
1969, I held several research posts at UK universities conducting marine geological
research, including a three month spell in the Lamont Geological Observatory
(Nyack, NY) funded by the Royal Society.
Ron Cherry is currently Halliburton's Global Business Manager for Open Hole
Services in the Wireline and Perforating Services business unit. After receiving a BS
degree in Electrical Engineering from the University of Tulsa in 1975 he joined
Schlumberger Well Services where he held various positions managing operations,
marketing and technology. In 1994 he joined NUMAR and served as the General
Manager until the company was acquired by Halliburton in 1997. Ron was
responsible for new product developments associated with NMR (MRIL products) for
several years and contributed to several patents and technical papers. Ron is now
responsible for all open hole logging products and services for Halliburton.

$\begin{array}{ll}\text { Songhua Chen } & \text { Songhua Chen is manager of Integrated Interpretation and Petrophysics in the } \\ \text { Research group at Houston Technology Center of Drilling and Evaluation Division of } \\ \text { Baker Hughes. He has been primarily involved in research and development of NMR } \\ \text { logging technology and integrated petrophysics. Prior to joining Western Atlas in } \\ \text { 1996, he was a research scientist for five years with Texas Engineering Experiment } \\ \text { Station in College Station, Texas, where he worked in the area of NMR and MRI } \\ \text { applications to multiphase flow in porous media. Songhua is an inventor on 26 U.S. } \\ \text { patents and authored and/or coauthored 73 papers. Songhua holds a B.S. from } \\ \text { Nanjing Institute of Technology in Nanjing, China and a Ph.D. from University of } \\ \text { Utah - Salt Lake City, U.S.A., both in physics. } \\ \text { Terry Hagiwara is a Petrophysics consultant at Aramco Services Company in } \\ \text { Terry Hagiwara } \\ \text { tool, EM and Nuclear, research for nearly 30 yrs. } \\ \text { Thomas Schenkel is a senior scientist at the Lawrence Berkeley National Laboratory } \\ \text { There he is leading the Ion Beam Technology group. He obtained his PhD in physics } \\ \text { from the Goethe-University in Frankfurt in 1997. He was a PostDoc at Lawrence } \\ \text { Livermore National Laboratory before joining LBNL in 2000. }\end{array}$





\subsection{Attendee List}

\begin{tabular}{|c|c|c|}
\hline Name & Affiliation & E-mail \\
\hline Ahmed Badruzzaman & Chevron & Ahmed.Badruzzaman@chevron.com \\
\hline Allen Gilchrist & Baker Hughes & W.GilchristQbakerhughes.com \\
\hline Andrew Pitts & Alpha Neutronics, Inc & Admin@alphneutronics.com \\
\hline Andy Weaver & Weaver Services Inc. & andy.weaver@wsicasedhole.net \\
\hline Anton Nikitin & Baker Hughes & Anton.Nikitin@bakerhughes.com \\
\hline Auto Tkabladze & Schlumberger & zuto@islb.com \\
\hline Avto Tkabladze & Schlumberger & avto@slb.com \\
\hline Ben Mayo & DHS/IP/Nuclear SSA & Mayocwm@aol.com \\
\hline Bill Rhodes & Sandia National Laboratory & wgrhode@sandia.gov \\
\hline Carlos Haramboure & Weatherford - Advantage Eng & carlos_haramboure@weatherford.com \\
\hline Charles Gallagher & Gammatron Inc. & gammatios swbell.net \\
\hline Chris Stoller & Schlumberger & CStoller Mslb.com \\
\hline Corban Gallagher & Gammatron Inc. & gammatios swbell.net. \\
\hline Cornelis Huiszoon & PathFinger - A Schlumberger Company & CHuiszoon@Pathfinder.slb.com \\
\hline David Madio & Schlumberger & dmadio@slb.com \\
\hline Ed Mitchell & Weatherford Int & ed.mitchellQweatherford.com \\
\hline Enrique Prati & Weatherford - Wireline R \& D & Enrique.Prati@weatherford.com \\
\hline Eric L. Rosemann, CSP & Gray Wireline Service, Inc. & eric.rosemann@graywireline.com \\
\hline Gabriel Teodovescy & Weatherford & gabriel.teodorescy@weatherford.com \\
\hline Gary A. Simpson & ConocoPhillips & Gary.A.Simpson@conocophillips.com \\
\hline Gary Fisher & Pioneer Wireline Svcs & GFisher@pioneerwireline.com \\
\hline Gordon Moake & Halliburton Energy Servcies & Gordon.Moake@Halliburton.com \\
\hline Grant Goodyear & Halliburton Energy Servcies & grant.goodyear@hall burton.com \\
\hline Greg Stanton & US Geological Survey & gstantonQusgs.gov \\
\hline Gregory Dale & Los Alamos National Lab & gedale@lanl.gov \\
\hline James Rutledge & Los Alamos National Lab & inutledgerglanlgox \\
\hline Jeff Griffin & PNNL & jeff.oriffin.opnl.ogy \\
\hline Jim R. Sharp & PLPS, Inc. & j.sharpoplpsinc.com \\
\hline Jim Sharp & Consultant & JSharp413@aol.com \\
\hline
\end{tabular}




\begin{tabular}{|c|c|c|}
\hline Joe Schwartzel & Consultant & jschwartzel-Dyfhconsulting.net \\
\hline Jonathan V. Thomas & US Geological Survey & jivthomas@usgos.gox \\
\hline Jos Jonkers & Weatherford & jos, jonkers, maca,weatherford.com \\
\hline Ka-Ngo Leung & Berkion Technology & kangoleung@pacbell_net \\
\hline Kenny Jordan & Association of Energy Service Companies & kiordan@aesc.net \\
\hline Kurt Stvack & University of Houston & kurt@kmstechnologies.com \\
\hline Kyriakos Tsorbatzohlou & Centronic & kt@entronic.us \\
\hline Larry Albert & Allied Wireline Services & larry.albert@alliedwireline.com \\
\hline Leonard Bond & PNNL & leonard.bond@onl_gov \\
\hline Libai Xu & PathFinger - A Schlumberger Company & lxu80pathfinder.slb.com \\
\hline Loren Roberts & Baker Hughes & loren robertselebalverhushes.com \\
\hline Madeliene Nawar & US Environmental Protection Agency & Nawar.Madeleine@epamail.epa_gov \\
\hline Maria Lorente & Schlumberger & mlorente1@slb.com \\
\hline Mark Shilton & QSA Global Inc. & Mark.Shilton@gsa-global.com \\
\hline Matt Coventry & Starfire Industries & mcoventry@starfireindustries.com \\
\hline Mike Evans & Schumberger & evans 19 glb.com \\
\hline Patrick Grissom & Pioneer Wireline Svcs & PGrissom Popioneemireline.com \\
\hline Paul Cooper & Halliburton Energy Servcies & Paul.Cooperohalliburton.com. \\
\hline Paul Morrison & Weaver Services Inc. & paul.morrison@wsicasedhole.net \\
\hline Paul Morrison & WSI Cased Hole & PaulQwsicasedhole.net \\
\hline Pedro Frigola & RadiaBeam Technologies & frigola@radiabeam.com \\
\hline Phillip R. Phelps & Probe Techonolgy Services, Inc. & phil.phelps@probe1.com \\
\hline Pingjun Guo & ExxonMobil Upstream Research Company & pingiun_quo@exxonmobil_com \\
\hline Rachel S. Browder & US NRC & Rachel.browderQnrc.gov \\
\hline Richard Clarke & Groundflow LTD & randomrichard@btinternet.com \\
\hline Richard Liu & University of Houston & CLIUQUH.EDU \\
\hline Rob Blize & Weatherford International & ron.blize@weatherford.com \\
\hline Robert D. Gallagher & NSSI & rdgallagher@nssihouston.com \\
\hline Robert J. Lewis & US NRC & robert.lewis_Qnrc.gov \\
\hline
\end{tabular}




\begin{tabular}{|c|c|c|}
\hline Robert Proul & Weaver Services Inc. & robert.proulfowsicasedhole.net \\
\hline Ron Cherry & Halliburton Energy Servcies & Ron.Cherry2OHalliburton.com. \\
\hline Ron D. Jeffcoat & Savannah River National Laboratory & ron.jeffcoat:@sml.doe gov \\
\hline Shuh-Haw Sheen & Argonne National Laboratory & sheen@anl.gov \\
\hline Songhua Chen & Baker Hughes & Songhua.Chen@bakerhughes.com \\
\hline Steve Bliven & Baker Hughes & Steven.Biven@bakerhughes.com \\
\hline Teruhiko Hagiwara & Aramco Services Company & Teruhiko.Hagiwara@aramcoservices.com \\
\hline Thomas Schenkel & Lawrence Berkeley National Laboratory & t schenkel@lbl_gov \\
\hline Tony Wu & Brightek Inc & tony@brightekinc.com \\
\hline Traci Moran & PNNL & traci.moran@pnl.gov \\
\hline Vincent Tany & Lawrence Livermore National Laboratory & $\operatorname{tany23@llnLgov}$ \\
\hline Ward Schultz & Consultant & ward.schultz@gmail.com \\
\hline Weijun Guo & Halliburton Energy Servcies & Weijun_Guo@Hallburton_com \\
\hline William J. Pike & National Energy Technology Laboratory. DOE & william.pike@nett.doe.gov \\
\hline Winston D. Seaman & Int'l Consultant Wireline & winston.seaman@sbcglobal.net \\
\hline
\end{tabular}



Appendix A 



\section{Appendix A}

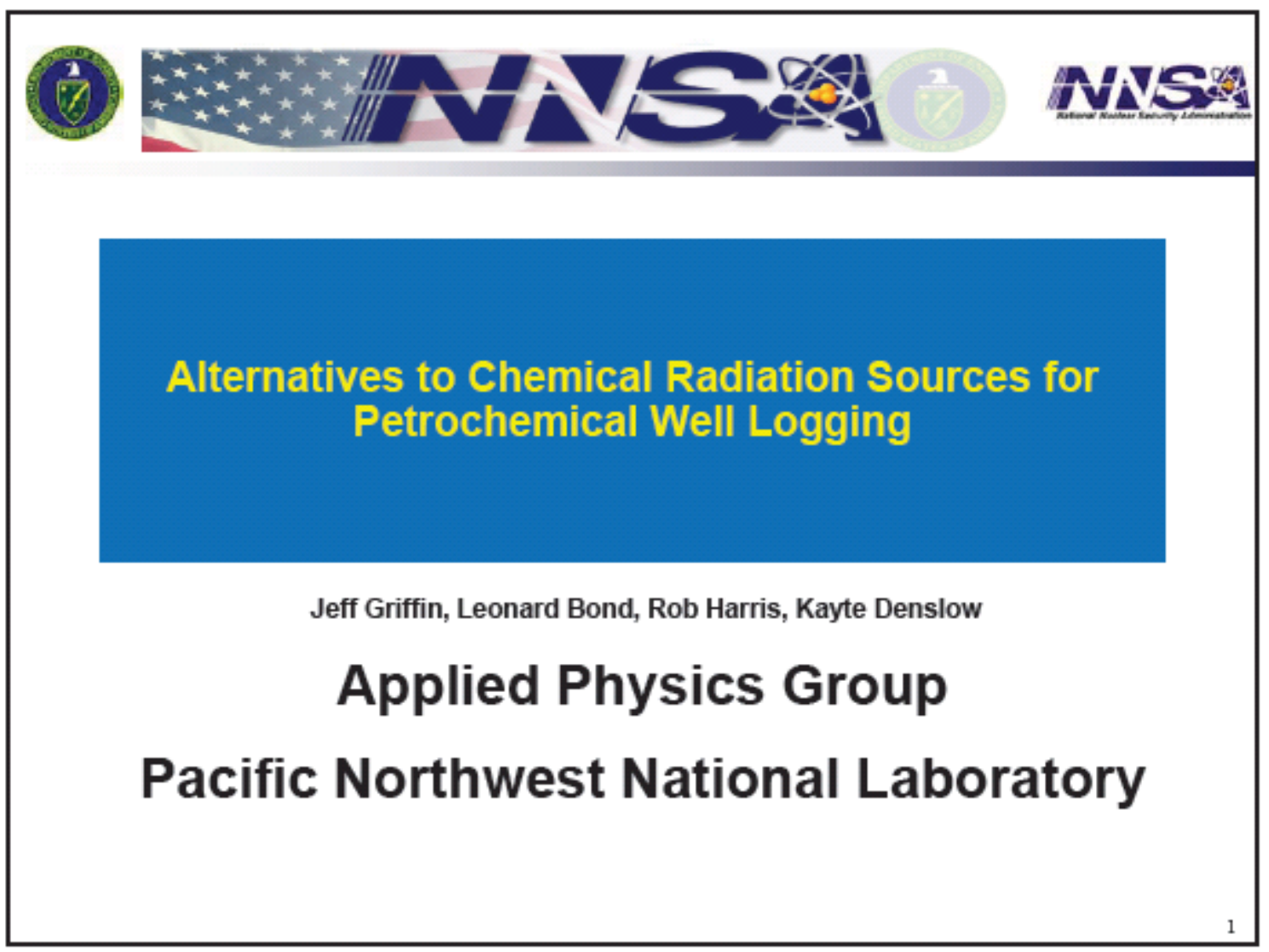




\section{Appreciation to Richard Liu}

University of Houston WLL and

Arthur Cheng

Society of Exploration Geophysicists

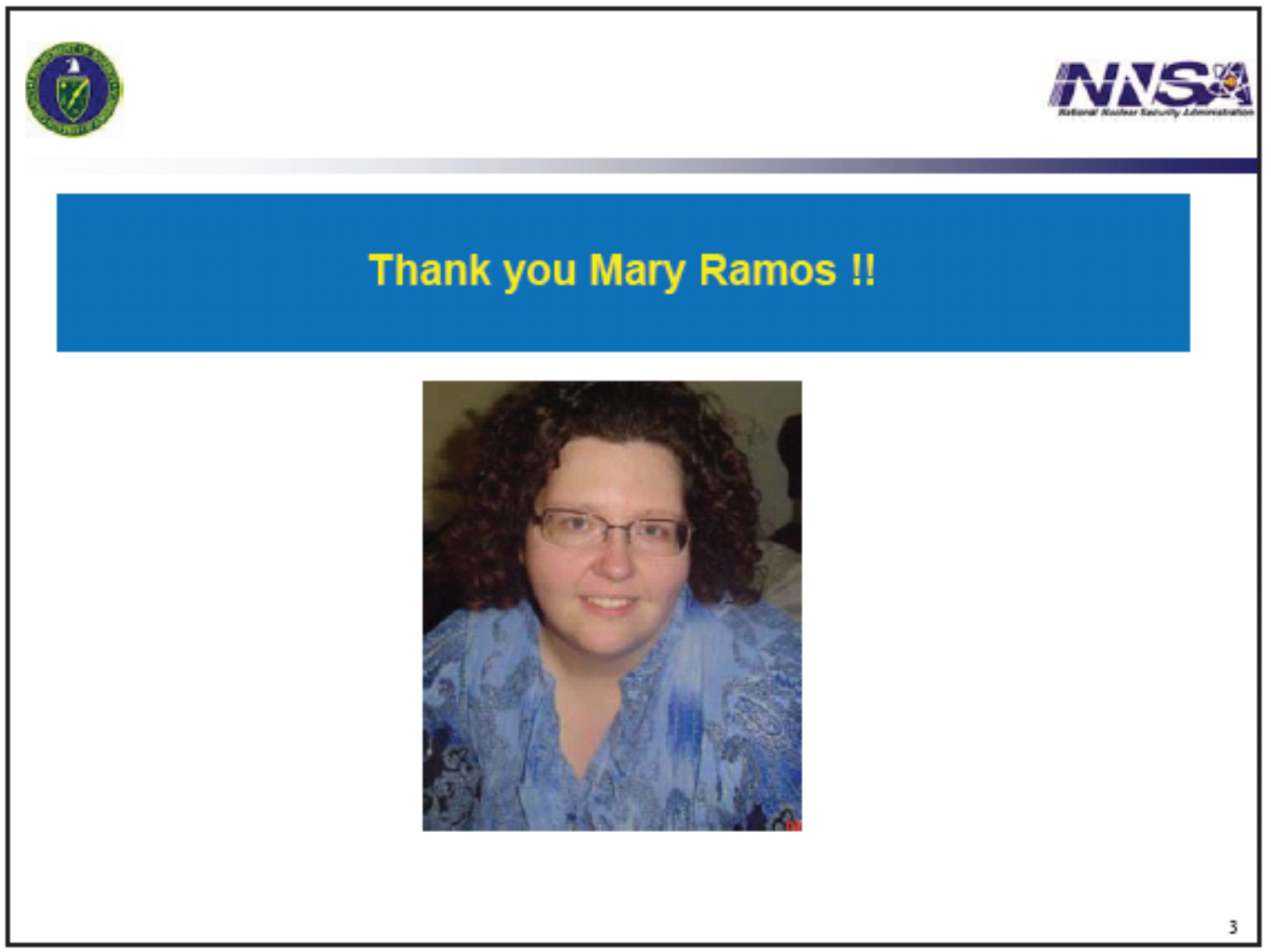

A.2 


\section{Objectives of NA-22 Program NNSA Non-proliferation R\&D

- Enhance US capabilities to detect and monitor foreign nuclear proliferation

- Strengthen international safeguards

- Reduce risk of malevolent use of IAEA Category 1 and 2 radioactive sources

\section{Radioactive Source Replacement Program}

- Motivated by 2008 National Academies Report (Phillips, et al 2008)

"Radiation Source Use and Replacement"

- Funded by USDOE National Nuclear Security Agency NA-22

- Investigate alternatives to use of chemical radiation sources, especially AmBe 


\section{Beginning $3^{\text {rd }}$ Year of Program}

- PNNL

- Survey of well logging technologies

- Assessment of replacement technologies

- Acoustic/ultrasonic

- Electromagnetic

- Passive nuclear (gamma spectroscopy)

- NMR

- Seismoelectric

- LBL and LANL

- Development of electronic neutron sources

\section{Workshop Goals}

NDSO

- Facilitate communications between national security policy makers and the petrochemical well logging industry

- Review current government programs related to radioactive source usage and regulation

- Review status of potential source replacement technologies 


\section{Workshop Deliverables}

- Useful one-on-one conversations

- List of government and industry contacts

\section{-Summary report}

\section{Feedback from SEG Annual Meeting}

"Neutron Source Replacement in Petrochemical Well Logging"

1) Cost and availability of AmBe in US are issues. Can Russian sources be used in the US ?

2) Restrictions on AmBe transport are viewed as excessive (compared with Europe)

3) DT neutron generators are a "dual use" technology. Will there be restrictions on their deployment and use?

4) Users want a neutron source with a spectrum that "looks like AmBe"

5) Small logging companies are the most vocal about retaining AmBe for re-logging production wells

6) Need validation of alternate or replacement neutron logging technologies

7) Large companies dominate LWD and use of electronic neutron sources 




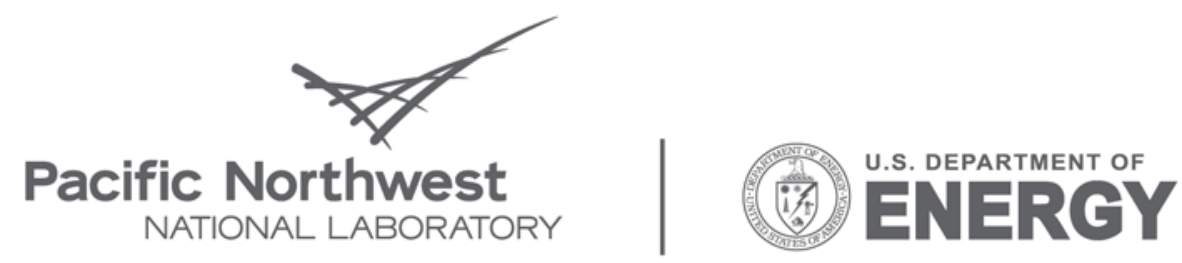

Proudly Operated by Battelle Since 1965

902 Battelle Boulevard

P.O. Box 999

Richland, WA 99352

1-888-375-PNNL (7665)

www.pnl.gov 